\title{
Enhanced loss of retinoic acid network genes in Xenopus laevis achieves a tighter signal regulation
}

Tali Abbou", Liat Bendelac-Kapon", Audeliah Sebag and Abraham Fainsod* Department of Developmental Biology and Cancer Research, Institute for Medical Research Israel-Canada, Faculty of Medicine, The Hebrew University of Jerusalem

"These authors contributed equally

${ }^{*}$ Corresponding author:

Prof. Abraham Fainsod

Department of Developmental Biology and Cancer Research

Institute for Medical Research Israel-Canada

Faculty of Medicine

The Hebrew University of Jerusalem

Jerusalem 9112102, Israel

abraham.fainsod@mail.huji.ac.il 


\begin{abstract}
Retinoic acid (RA) is a major regulatory signal during embryogenesis produced from vitamin A (retinol) by an extensive, autoregulating metabolic and signaling network to prevent fluctuations that result in developmental malformations. Xenopus laevis is an allotetraploid hybrid frog species whose genome includes L (long) and S (short) chromosomes from the originating species. Evolutionarily, the X. laevis subgenomes have been losing either L or S homoeologs in about $43 \%$ of genes to generate singletons. In the RA network, out of the 47 genes, about $46 \%$ have lost one of the homoeologs, like the genome average. In contrast, RA metabolism genes from storage (retinyl esters) to retinaldehyde production exhibit enhanced gene loss with 75\% singletons out of 28 genes. The effect of this gene loss on RA signaling autoregulation was studied. Employing transient RA manipulations, homoeolog gene pairs were identified in which one homeolog exhibits enhanced responses or looser regulation than the other, while in other pairs both homoeologs exhibit similar RA responses. CRISPR/Cas9 targeting of individual homoeologs to reduce their activity supports the hypothesis where the RA metabolic network gene loss results in tighter network regulation and more efficient RA robustness responses to overcome complex regulation conditions.
\end{abstract}

\title{
Keywords:
}

Retinoic acid; Signaling robustness; Xenopus; Gene regulation; Genome evolution; Gene duplication; homoeolog 


\section{Introduction}

Retinoic acid (RA) signaling is one of the major regulatory pathways active during embryogenesis and it controls numerous developmental processes [1-4]. RA is produced in the body from nutritional sources containing vitamin A (retinol, ROL) and other retinoids, or carotenoids [5,6]. This metabolic network involves multiple enzymes active in the conversion of these substrates into RA, or the storage of retinoids as retinyl esters to survive periods when the nutritional sources of retinoids or carotenoids are diminished or lacking [5,7-10]. Increased or decreased RA signaling levels can result in severe developmental malformations [8,11-14]. For this reason, the RA metabolic and signaling network exhibits efficient self-regulation to overcome fluctuations in this signaling pathway elicited by dietary changes, environmental toxicity, or genetic polymorphisms [15-26]. The autoregulation of the RA network by RA levels is instrumental to maintaining pathway robustness in response to hampering mechanisms $[27,28]$.

For over half a century, gene duplication has been studied as one of the processes important for the evolution of species [29-31]. Following duplication of a gene or gene family, one of the copies can be lost, or one member retains the original function and regulation whereas the extra copy can gain novel functions, called neofunctionalization and regulation. Generally, duplications occur on a small scale involving restricted genomic regions, but in extreme cases, gene duplication of all the genes present in the genome is the result of polyploidization by whole-genome duplication (WGD) [29]. Xenopus laevis, the African clawed frog, was proposed to have arisen by interspecific hybridization of two related diploid species followed by WGD making it an allotetraploid species [32]. From sequence analysis of the Xenopus laevis genome, it was concluded that the two ancestral originating species separated about 34 million years ago and the allotetraploid event occurred about 17-18 million years ago. X. laevis inherited half of its genome from each ancestor, resulting in two distinct subgenomes present in a diploid condition: L and S, for long and short chromosomes, respectively [32]. 
As a result of a WGD event, one of the gene copies may diverge, probably together with other genes, co-evolving as a complex system to achieve neofunctionalization or subfunctionalization [31]. Alternatively, it has been proposed that sometimes following a burst of increase in genome complexity, there is a long process of genome reduction $[33,34]$. During the genome reduction process following a WGD event, one of the gene copies might be lost or mutated into a pseudogene [35]. Analysis of the genome of $X$. laevis and its transcriptome clearly identified many instances of the $\mathrm{L}$ and $\mathrm{S}$ genes and their respective transcripts [32,36-39]. Also important, these studies identified a process of gene loss that encompasses today about $43 \%$ of protein-coding genes [32]. Most of this gene loss took place in the S subgenome. Detailed genome analysis also revealed high $(>85 \%)$ conservation of both (L and S) gene copies, i.e., homoeologs, among genes encoding DNA binding proteins, transcription factors, the Wnt, Hh, Notch, FGF, TGFß, and Hippo signaling pathways [32,40-42]. The inverse situation, enhanced gene loss, was observed among the genes encoding DNA repair proteins (79\% singletons). This high rate of singletons was attributed to either a lack of selective pressure where one enzyme encoding locus is sufficient or to functional incompatibility among homoeologs leading to deletions [32].

We analyzed the RA signaling network in X. laevis and uncovered an average distribution of homoeologs and singletons compared to the genomic average. However, deeper analysis of the RA metabolic and gene regulatory network revealed that among the enzymatic components necessary for retinaldehyde (RAL) production, and retinoid storage and retrieval there is a high incidence of gene loss, resulting in about $75 \%$ singletons. For the rest of the network, from RAL to RA production, RA disposal and gene regulation, most genes (about 95\%), are present as homoeolog pairs. We studied the possibility that the enhanced gene loss in the RA metabolic network leading to RAL production is related to the regulation of the RA signal to prevent teratogenic outcomes. A transient RA manipulation approach followed by kinetic analysis of the recovery period revealed the presence of both tightly regulated (restricted responses, low RA fluctuation sensitivity) and loosely regulated (enhanced responses, high RA change sensitivity) genes. We speculated that homoeolog pairs with markedly different RA 
responses would degrade the robustness response to RA fluctuations, therefore we used CRISPR/Cas9 to target specific homoeologs. Our results showed that among homoeolog pairs with similar RA responses, individual knockdowns resulted in similar recovery kinetics from the RA treatment. In contrast among homoeologs with diverged RA responses, knockdown of the tightly-regulated homoeolog impairs the kinetic recovery response, whereas, targeting the loosely regulated homoeolog improves the RA robustness response. These results support our hypothesis proposing that enhanced gene loss of the RA network components might lead to an improved robustness response by reducing the number of genes to be regulated, specifically removing genes with enhanced responses to RA fluctuation.

\section{Materials and Methods}

\subsection{Embryo Culture and Treatment}

Xenopus laevis frogs were purchased from Xenopus I or NASCO (Dexter, MI or Fort Atkinson, WI, United States). Experiments were performed after approval and under the supervision of the Institutional Animal Care and Use Committee (IACUC) of the Hebrew University (Ethics approval no. MD-17-15281-3). Embryos were obtained by in vitro fertilization, incubated in 0.1\% Modified Barth's Solution and Hepes (MBSH), and staged according to Nieuwkoop and Faber [43]. All-trans retinoic acid and Dimethyl sulfoxide (DMSO) were purchased from Sigma-Aldrich (St. Louis, MO, United States). Stock solutions of RA were prepared in DMSO. For transient RA treatment, embryos were placed in $10 \mathrm{nM}$ or $25 \mathrm{nM}$ RA from late blastula (st. 9.5) and washed two hours later, at early gastrula (st. 10.25) by three changes of $0.1 \% \mathrm{MBSH}$ and further incubated in fresh $0.1 \%$ MBSH for the desired time. Samples were collected 1, 1.5, 2, and 2.5 hours after washing.

\subsection{Quantitative reverse transcription real-time PCR ( $q P C R$ )}

Total RNA from embryos was extracted with Aurum ${ }^{\mathrm{TM}}$ Total RNA Mini Kit (BioRad). cDNA was synthesized using iScript cDNA Synthesis Kit (Bio-Rad). The real-time 
PCR reactions were performed using the CFX384 Real Time System (Bio-Rad) and iTaq Universal SYBR Green Supermix (Bio-Rad). Each experiment was repeated at least three independent times and each time the samples were run in triplicate. slc35b1.L was used as the housekeeping reference gene. The primers used for qPCR analysis are listed in Table 1.

\subsection{Generation of CRISPant embryos}

For gene-specific single guide RNA design (sgRNA), genomic DNA sequences were selected from Xenbase.org [44] for the L and S homoeologs when present and analyzed using CRISPRdirect [45] and CRISPRscan [46] for target site search. Computational estimation of the sgRNA efficiency was determined using the inDelphi software $[47,48]$. For the generation of F0 CRISPant embryos, we injected one-cell stage embryos with Cas9 ribonucleoprotein (RNP) complexes employing the two-RNA component (crRNA:tracrRNA) approach [49]. Briefly, chemically synthesized and modified for stability (Alt-R) RNAs (crRNA and tracrRNA; IDT, USA) (Table 1) were annealed to generate the double guide complexes (crRNA:tracrRNA) and were incubated (10 min at $37^{\circ} \mathrm{C}$ ) with S. pyogenes Cas9 protein (IDT, USA) to generate RNP complexes. Eight nanoliters of the RNP complex solution were injected into the cytoplasm of one-cell stage embryos.

To determine the efficiency of indel induction, genomic DNA was extracted from 5 individual embryos at mid-gastrula (st. 11) or later employing the GenElute Mammalian Genomic DNA Miniprep Kit (Sigma). The genomic region containing the CRISPR/Cas9 targeted region was PCR amplified using a nested PCR approach (Table 1) and the size-selected and cleaned product was sequenced. Genome editing efficiency was analyzed by decomposition analysis [50] using the Synthego ICE algorithm [51].

\subsection{Statistical analysis}

All statistical comparisons were carried out using the Prism software package (Graph Pad Software Inc., San Diego, CA). Results are given as the mean \pm standard error of the mean (SEM). Tests used were the 2-tailed t-test for two-sample comparisons, Dunnett's 
(ANOVA) multiple comparisons test, or Fisher test. Differences between means were considered significant at a significance level of $\mathrm{p}<0.05$.

\section{Results and Discussion}

\subsection{Conservation of the RA network}

In a recent extensive data mining effort searching the KEGG and Xenbase databases $[44,52]$ and the literature, we assembled the putative components of the RA metabolic and signaling network during early embryogenesis [1,6,9]. To determine the composition of the RA network during gastrula in Xenopus laevis embryos we assessed which components are expressed during this developmental stage based on analysis of transcriptomic data sets [27,53,54] and corroborated the gastrula expression by quantitative RT-PCR (qPCR) [55]. This view of the RA metabolic and signaling network exhibits a rather uncommon characteristic that for each enzymatic step, multiple genes encoding enzymes have been described that are capable of performing the same reaction (Fig. 1). For some of the reversible reactions, such as the oxidation of ROL to RAL and the corresponding reduction of RAL to ROL, a preferred activity has been identified, but the reverse reaction might be possible under certain conditions [56-58]. Because it is necessary to maintain non-teratogenic levels of RA at these stages, there appear to be several ways to control levels of RA signaling. Substrate availability for the retinaldehyde dehydrogenase enzymes that oxidize RAL to RA, the ALDH1A subfamily, is controlled by the presence of multiple enzymes that reduce RAL back to ROL $[10,13,15,25,59-61]$. Levels of signaling can additionally be controlled by regulating the spatial-temporal expression of the many RA metabolic and gene regulatory network components, including the RA nuclear receptor families (RAR and RXR) and retinoidbinding proteins [62-64].

Analysis of the allotetraploid status of the genes encoding all the identified RA network components in the Xenopus laevis genome revealed that in 25 out of 47 genes both the L and S homoeologs [32] have been retained during evolution (Fig. 1; Table 2). Thus, 22 genes (46.8\%) in the RA network have lost one of the homoeologs, bringing this metabolic and signaling network close to the genomic average (43.6\%) of singletons 
among protein-coding genes [32]. This observation seemingly contradicts previous studies of other main signaling pathways critical for normal embryogenesis, like TGFß, FGF, Wnt, Hh, Notch, Hippo, and of transcription factors for which the conservation of the L and S homoeologs is very high (>83.3\%; Table 2)[40-42].

Further analysis of the distribution of homoeologs and singletons within the RA network genes, however, revealed a surprising, non-random distribution of gene loss events (Fig. 1). Among the enzymes involved in the metabolic steps leading up to the production of RAL, including retinoid storage, about $75 \%$ of the genes (21 out of 28) were encoded as singletons (Fig. 1; Table 2). Interestingly, for genes involved in the oxidation of RAL to RA, hydroxylation of RA, or actual RA-driven gene regulation, almost all (94.8\%; 18 out of 19) are still encoded by both L and S homoeologs (Fig. 1; Table 2).

This suggests a preferential loss of homoeologs involved in the production of RAL, regulation of RAL production, or storage of retinoids. One possible explanation for this asymmetrical gene loss in the metabolic side of the RA network could be the observation that RAL availability for oxidation by retinaldehyde dehydrogenases is like a "commitment" step (Fig. 1). The oxidation of RAL to RA by the ALDH1A1, ALDH1A2, and ALDH1A3 enzymes cannot be reversed and either promotes RA-driven gene regulation or the RA produced has to be neutralized and degraded. RA signaling is one of the major embryonic signaling pathways dependent on the maternal nutritional status and its function can be altered by environmental factors [5,15-17]. Fluctuations in RA signaling, increase or decrease, can be extremely teratogenic. Therefore, we explored the possibility that the extensive gene loss observed preferentially achieves tighter regulation of the RA signal, providing an evolutionary advantage.

To assess whether this preferential gene loss in the RA metabolic and generegulatory pathway was restricted to RA signaling, we also analyzed the genomic evolution of two additional nuclear receptor signaling pathways closely linked to RA: vitamin D and thyroid hormone signaling $[65,66]$. Thyroid hormone biosynthesis and 
signaling in Xenopus includes 23 genes out of 52 that are already singletons (44.2\%), bringing this pathway to the genomic average with no obvious distinctive distribution (Table 2). Interestingly, vitamin $\mathrm{D}$ biosynthesis and gene regulation exhibit a distribution resembling the RA network where part of the pathway is rich in singletons (Fig. 2). Also, in this case, the whole pathway (21 genes) exhibits $38 \%$ singletons (8 genes) close to the protein-coding average (Table 2) [32]. But, from the production of cholecalciferol (Vitamin $\mathrm{D}_{3}$ ) the pathway has 6 genes out of 9 that are already singletons (Fig. 2; Table 2). These 66.7\% singletons in the vitamin D-specific part of the network show a preferential loss of genes involved in metabolism and gene regulation by this ligand.

As both the RA and vitamin D signaling pathways involve biosynthesis of the regulatory ligand through a metabolic pathway, to assess the generality of this observation we explored the L or $\mathrm{S}$ gene loss in additional metabolic pathways. For the de novo purine biosynthesis pathway we scored 7 genes out of 15 that are already singletons (Table 2). The $47 \%$ singleton status is close to the genomic average suggesting the normal rate of gene loss for coding sequences. Analysis of glycolysis + gluconeogenesis + Krebs cycle identified 9 singletons among 44 genes (20.4\%), which is a low singleton proportion suggesting conservation of both homoeologs in these metabolic pathways (Table 2). Analysis of the folic acid metabolic network indicated the reverse: a high proportion of singletons. From the information in KEGG, we identified 27 enzyme-encoding genes in the X. laevis genome out of which 19 (70.4\%) are encoded by singletons (Table 2), indicating a preferential loss of one of the homoeologs during evolution.

Based on the analysis of homoeolog loss in the Xenopus laevis genome to date [32,4042], signaling pathways and metabolic networks can be classified into three groups. There are pathways that exhibit homoeolog retention rates similar to the protein-coding gene average in the whole genome. From our analysis, we identified the thyroid hormone synthesis and signaling, vitamin D biosynthesis and signaling, de novo purine biosynthesis, and RA metabolism and signaling pathways as belonging to this group (Table 2). The second group includes previously analyzed signaling pathways described 
as having very high homoeolog retention rates (low or suppressed singletons)[32,4042], and we added Krebs cycle, glycolysis, and gluconeogenesis to this group (Table 2). Our analysis identified the third group as having a high rate of gene loss creating a high proportion of singletons (Table 2). Interestingly, apart from the folate metabolic network, for both RA metabolism and vitamin D biosynthesis and signaling, the high rate of homoeolog loss localizes to a specific region of the pathway (Figs. 1 and 2).

\subsection{Genomic changes in the loss of a homoeolog}

The high incidence of singletons in the RA metabolic network from retinyl ester storage to the production of RAL prompted us to try to understand the genomic rearrangements that resulted in this enhanced homoeolog loss that involved 21 out of 28 genes (Table 2). We focused our analysis on enzymes with alcohol dehydrogenase activity to oxidize vitamin A to RAL (Producers 1); enzymes, mainly of the short-chain dehydrogenase/reductase family, that reduce RAL to retinol (Suppressors); and proteins involved in B-carotene cleavage to RAL (Producers 3) (Fig. 1; Table 3). We compared the appropriate genomic regions between the L and S chromosomes choosing the first pair of conserved genes flanking the deleted or rearranged region as boundaries (Table 3). Using these flanking genes, we could determine the distance between them in the L and S chromosomes and analyze the region between them (Table 3). This type of analysis revealed cases in which single or multiple genes were deleted. Also, the length of the modified region changed from 0.1 to $410 \mathrm{~Kb}$ (Table 3). We could group the rearrangements into three groups. The first group represents singletons in which the loss of a homoeolog involved a relatively small $(0.1-36 \mathrm{~Kb})$ and simple deletion (Fig. 3A; Table 3). The second group involved large (102-410 Kb) deletions (Fig. 3B; Table 3). In the third group, we identified large deletions (81 and $238 \mathrm{~Kb}$ ) combined with extensive rearrangement of the genomic region (Fig. 3C; Table 3). These results show that most deletions leading to the loss of a homoeolog are relatively simple although the genomic region lost can be small or very large. In a few cases, the loss of a homoeolog involved complex genomic rearrangements in addition to the deletion of genes. In the locus on chromosome 1 (Fig. 3C) there are multiple adh genes suggesting 
the possibility that this region contained duplicated sequences that could contribute to the rearrangements in this genomic region. On chromosome 9_10 we also observed a complex deletion but did not observe gene duplications that could contribute to its creation.

\subsection{Expression overlaps and responsiveness of $R A$ network components}

Our recent analysis of the RA metabolic and signaling network revealed a high degree of robustness following disruption of this pathway within the physiological range [27]. Moreover, this study showed that enzymes performing the same metabolic reaction and expressed in partially overlapping patterns might be regulated differently. These differential responses to RA fluctuation are part of the mechanism to keep this critical signal within an appropriate, non-teratogenic range [27]. One possibility for the preferential loss of homoeologs in genes encoding RA network components is the selective or non-selective reduction of gene copies to achieve tighter regulation of the signal. To begin exploring these possibilities as possible driving forces for gene loss, we searched for gene pairs expressed during gastrula stages that have the same enzymatic activity but one of them is a singleton and the other is still presented as a homoeolog pair. Based on our previous studies we chose $r d h 10$ and $s d r 16 c 5$ for genes encoding enzymes that oxidize ROL to RAL (Producers 1), dhrs3 and rdh14 for genes encoding enzymes that reduce RAL to ROL (Suppressors), and aldh1a2 and aldh1a3 for genes encoding enzymes that oxidize RAL to RA and for which no singletons are known (Producers 2) (Fig. 1). The temporal pattern of expression was determined for these genes including analysis of the individual homoeologs by qPCR (Fig. 4). In all three gene groups, we observed extensive overlap in the temporal expression pattern between the selected singleton and at least one of the homoeologs of the paired gene with similar enzymatic activity (Fig. 4A-C). While sdr16c5 (singleton) exhibits a pattern similar to the rdh10.S homoeolog both having significant maternal expression (Fig. 4A), the rdh10.L homoeolog is mainly expressed zygotically. Among the Suppressors tested (Fig. 4B), rdh14 exhibits what might be maternal transcripts, and its expression levels decline during gastrulation (Fig. 4B). Both dhrs3 homoeologs retain extensively 
overlapping temporal expression patterns that peak at late gastrulation and subsequently decline (Fig. 4B). The retinaldehyde dehydrogenase encoding genes aldh1a2 and aldh1a3 exhibit mostly zygotic expression patterns with a marked upregulation with the onset of gastrulation (Fig. 4C). These expression patterns support the partial overlap between the genes selected and are part of the RA network during gastrulation.

For the four homoeolog pairs studied, we observed divergence in their temporal expression patterns. In the extreme case, rdh10.S exhibits high levels of maternal transcripts and a gradual decline during gastrula stages, whereas $r d h 10 . \mathrm{L}$ expression is activated after the midblastula transition as a zygotic gene (Fig. 4A). A similar expression pattern for this homoeolog pair was determined from transcriptomic data [32]. This divergence in temporal expression patterns suggests changes in regulatory elements and initial subfunctionalization of the homoeologs [36]. For two of the other homoeolog pairs, dhrs3 and aldh1a3, there are subtle differences in their temporal expression patterns, with extensive overlap but also new gene-specific changes (Fig. $4 \mathrm{~B}, \mathrm{C})$. In contrast, the aldh1a2 homoeologs exhibit temporal expression patterns that are very similar (Fig. 4C). Interestingly, the early expression of aldh1a2 at the onset of gastrulation has been linked to the onset of RA signaling as the enzyme encoded by this gene is the last component needed to complete the biosynthesis of RA [15,67-70]. Also, we have shown that within the aldh1a gene family, aldh1a2 is expressed at the highest levels during early gastrula stages [15]. Thus, there appears to be selective pressure to conserve this expression pattern and the early gastrula activity of aldh1a2.

To better understand the contribution of these genes to the response of the RA network to fluctuations in ligand levels, we studied the response of these genes to subtle manipulation of RA levels. Analysis of the RA content of Xenopus laevis embryos during early gastrula estimated that they contain about 100-150 nM RA [71-77]. To perform physiologically-relevant manipulations of RA we increased that level by about 10\%-25\% using $10 \mathrm{nM}$ and $20 \mathrm{nM}$ treatments, respectively [27]. Embryos were treated from late blastula to early gastrula (st. 10.25) and collected for expression analysis by qPCR. This analysis revealed robust responses by the dhrs3 homoeologs $(\mathrm{p}<0.0001)$ and 
weak (not significant) responses by the rest of the genes tested (Fig. 5). The selfregulation of the RA metabolic and signaling network to maintain or restore normal signaling levels is widely accepted, and the transcriptional responses of aldh1a2, cyp26a1, dhrs3, and rdh10 to increased RA levels are the basis of this suggestion [18$24,70,78]$. In a recent study, we performed a detailed analysis of the RA responsiveness and requirement for the RA network genes expressed during early gastrula [27]. While some genes exhibited robust and concentration-dependent responses, others showed no significant changes in response to RA fluctuations. Also, the same gene was shown to exhibit different responsiveness at different developmental stages [27]. These changes in responsiveness could be explained in part by the different temporal expression patterns and the RA responsiveness of the homoeologs that were not addressed in previous studies.

\subsection{Homoeolog response to transient $R A$ manipulation}

The enhanced homoeolog gene loss observed within the RA metabolic network leading to the production of RAL raised the question as to the possible selective pressure driving this phenomenon. Maintenance of normal RA signaling levels is central for the prevention of the teratogenic effects of increased or decreased RA signaling levels $[13,21,71,79-82]$. Thus, homoeolog gene loss might be a "solution" to achieve tighter signaling regulation, i.e., robustness [27]. Several models can be suggested that could drive this gene loss to achieve higher RA signaling robustness. One possibility is that one of the homeologs in the pair has a less efficient or enhanced sensitivity, "noisier" regulation, and this gene is lost preferentially to reach tighter regulation. A "noisy" gene could mediate fast responses and might not necessarily be advantageous to lose. Alternatively, coordinated regulation of numerous genes performing the same enzymatic function might be more complicated to achieve, so having fewer genes would provide tighter regulation. To discriminate between these possibilities, we took advantage of an experimental protocol for transient RA manipulation and kinetic monitoring of the recovery process by qPCR (Fig. 6A) [27]. This assay allows us to monitor the robustness response as it takes place by analyzing 
the expression changes of RA network components and downstream, RA-regulated genes. To perform physiologically relevant RA manipulations, based on our homoeolog responsiveness analysis (Fig. 5) and our previous studies [27], embryos were treated with $10 \mathrm{nM}$ and $25 \mathrm{nM}$ all-trans RA for 2 hours from late blastula to early gastrula (st. 10.25). The treatment was terminated by washing (T0) and samples were collected during the recovery period at 1.0, 1.5, 2.0, and 2.5 hours post-washing (T1, T1.5, T2, and T2.5, respectively) (Fig. 6A). RNA samples were prepared for comparative expression analysis to control samples. For enzymes that oxidize ROL we analyzed rdh10.L, rdh10.S, and sdr16c5 (Producers 1), for enzymes that reduce RAL to ROL we chose dhrs3.L, dhrs3.S, and rdh14 (Suppressors), and among the genes that produce RA (Producers 2), we studied both homoeologs of aldh1a2 and aldh1a3 (Fig. 1). For each homoeolog or singleton, the relative expression (fold change; • ) was calculated at each time point relative to the expression in sibling control embryos at the same developmental stage, and the average - of four biological replicates was calculated. Analysis of $r d h 10 . L, r d h 10 . S$, and $s d r 16 c 5$ revealed very slight fluctuations of all three genes irrespective of whether $10 \mathrm{nM}$ or $25 \mathrm{nM}$ RA was used for the treatment (Fig. $6 \mathrm{~B}, \mathrm{C})$. These weak responses are in agreement with the previous results of the RA responsiveness in which all three genes responded similarly (Fig. 5A). Also, these results suggest that none of the genes exhibits heightened responses in our experimental protocol which aims to mimic physiological RA fluctuations.

Analysis of the genes encoding enzymes preferentially involved in reducing RAL to ROL, dhrs3.L, dhrs3.S, and $r d h 14$, revealed the hypothesized situation where one of the homoeologs exhibits an enhanced response to changes in RA levels and delayed restoration of normal expression levels. Expression of dhrs3.L shows the strongest upregulation at $\mathrm{T} 0$ irrespective of the amount of RA employed of the three genes analyzed (Fig. 6D,E). By comparison, dhrs3.S shows a robust but weaker response at the end of the treatment, and $r d h 14$ only exhibits a weak response. Importantly, while dhrs3.S and rdh14 reached almost normal expression levels ( $<2.3$ fold) at the end of the recovery period (T2.5), dhrs3.L is still significantly up-regulated (>2.9 fold)(Fig. 6D,E). Analysis of the aldh1a2 and aldh1a3 homoeologs revealed that by the end of the transient treatment 
(T0), some of the homoeologs exhibit a clear up-regulation, but already one hour into the recovery period all genes are almost back to normal expression levels (Fig. 6F, G). These results show that the transient RA treatments can induce robust responses (dhrs3), but many of the genes studied exhibit mild expression changes and strong robustness responses, i.e., return to normal levels. A previous study that employed the same transient RA manipulation protocol but collected samples up to 5.5 hours after washing showed efficient recovery to normal expression levels of most RA network genes [27].

To make comparisons between samples, genes, or biological replicates easier, we calculated the fold change of each gene for all time points $(\bullet)$ and we summed up the values into a summary fold change score $(\bullet \bullet)$. This score should be low for tightly regulated genes and high for enhanced responders with slow recovery to normal values. We calculated this regulation tightness score for all genes studied (Table 4). The results show that for genes exhibiting moderate or limited gene responsiveness to RA and expression changes throughout the recovery period, $r d h 10 . \mathrm{L}, r d h 10 . S, s d r 16 c 5, r d h 14$, aldh1a2.L, and aldh1a2.S, the average • - score ranged from 4.3 to 5.8 (Table 4). For each one of these genes, the difference in the amount of RA added had a very limited effect on the variation in their expression. For genes with higher fluctuation in their expression, aldh1a3.L, aldh1a3.S, dhrs3.L, and dhrs3.S, the • • score increased in correlation with the kinetic analysis result (Table 4; Fig. 6). The score for dhrs3.L reached - >28 making it the least tightly regulated gene or the gene with the most extreme responses to RA fluctuations of those analyzed. Importantly, both singletons studied, rdh14 and $s d r 16 c 5$ exhibited tight regulation with low responsiveness to RA fluctuations even though they have been shown to be involved in vivo in the metabolism of RA [8385].

\section{5. $R$ A responsiveness in homoeolog CRISPant embryos}

The results of the individual homoeolog responses to transient RA manipulation identified gene pairs that represent all the possibilities initially suggested. The $r d h 10$ and aldh1a2 genes have tightly and similarly RA-regulated homoeolog pairs. Similar but 
slightly enhanced responses were observed for the aldh1a3 homoeologs, whereas the dhrs3 homoeolog pair showed strong responses to RA changes and marked differences between the L and S genes. To begin to address the possible force driving the gene loss that gives rise to singletons, we took advantage of the CRISPR/Cas9 technology to create a partial, homoeolog-specific gene loss. We designed homoeolog-specific single guide RNAs (sgRNA) for the $d h r s 3$ and $r d h 10$ genes to knock down the expression of one homoeolog without affecting the second one. We also designed a sgRNA targeting the $s d r 16 c 5$ singleton. To determine the efficiency of the sgRNAs, DNA was extracted from CRISPant embryos and the genomic region containing the sgRNA targeted sequence was PCR-amplified and sequenced. Decomposition analysis of the sequence traces $[50,51]$ provided a quantitative assessment of the genome editing efficiency. Analysis of the sequencing traces demonstrated the creation of indels around the sequence targeted by the sgRNA and the deterioration of the sequencing quality (Supplementary Fig. S1). According to the decomposition analysis, we observed a relatively robust effect of the sgRNAs inducing indels (Supplementary Fig. S1).

To study the effect of losing one of the homoeologs on the RA robustness response, embryos were injected at the one-cell stage with the appropriate sgRNA/Cas9 riboprotein complex to generate CRISPant embryos, which were then subjected to the transient RA manipulation protocol using low RA concentrations (10 nM)(Fig. 6A). RNA samples were collected at T0 (wash) and at 1.0, 1.5, 2.0, and 2.5 hours after treatment termination. To understand the effect of this gene knockdown on the RA signaling levels, we analyzed the expression of a panel of RA-regulated genes including cyp26a1.L, hoxd1.L/S, hoxa1.L, hoxa1.S, hoxa2.L/S, hoxb4.S, hoxb1.L, and hoxb1.S (Fig. 7 and Supplemental Fig. S2). Comparison at T0 of the expression levels of RA-responsive genes between RA treatment and $r d h 10$, dhrs3, and sdr16c5 CRISPants treated with RA supported the efficiency of the sgRNAs (Fig. 7A,B and Supplemental Fig. S2A,B). The RA treatment alone induced up-regulation of all RA targets ranging from 3.6 to 35 fold increase, while RA treatment of the $r d h 10 . \mathrm{L}, r d h 10 . S$, and $s d r 16 c 5$ CRISPants resulted in a weaker RA-induced up-regulation irrespective of the gene being knocked down (Fig. 7A and Supplemental Fig. S2A). In agreement with the similar and limited responses to 
RA exposure (Fig. 6B,C), the three genes individually targeted, rdh10.L, rdh10.S, and $s d r 16 c 5$, resulted in similar outcomes. This response of the RA target genes agrees with the suggestion that between similarly regulated RA network genes that encode enzymes performing the same metabolic reaction, their loss is equivalent in the early embryo. Maintenance of the singletons might reflect different spatial-temporal regulation to perform the same enzymatic reaction in different tissues in the embryo or the adult.

Kinetic analysis of the RA robustness response in the $r d h 10 . \mathrm{L}, r d h 10 . S$, and $s d r 16 c 5$ CRISPants was monitored by following the expression of the RA target genes during the recovery period (T0-T2.5; Fig. 6A). To better understand the contribution of the RA network components studied, the CRISPant samples treated with RA were compared to siblings treated with RA only. In most instances, knockdown of each of these three genes had a mild effect on the gene expression reducing the response to the transient RA treatment (Fig. 7C,E,G,I and Supplemental Fig. S2C,E,G,I). It is important to note that weaker responses in the CRISPants treated with RA support a tighter regulation of the signal as a result of the phenocopy of the gene loss. In a few instances we observed enhanced responses to the RA exposure mainly linked to the rdh10.L CRISPant (Fig. 7E and Supplemental Fig. S2C), the rest of the samples exhibited a more restricted response to RA exposure supporting a tighter regulation. To simplify the comparative analysis between CRISPants, we calculated the regulation tightness score $(\bullet \bullet)$ of the RA target genes for all time points compared to the response in RA-treated embryos (Fig. 8A). The scores for the RA-regulated genes in the three RA-treated CRISPants showed that all of them reduced the target gene expression changes. This result suggests that in the case of rdh10.L, $r d h 10 . S$, and $s d r 16 c 5$, the gene activity reduction results in tighter regulation of the RA robustness response in agreement with a gene loss model for better regulation of the signal. Also in this analysis, we can observe the enhanced responses linked to the rdh10.L CRISPant (Fig. 8A).

The dhrs3 homoeologs exhibit enhanced responses to the transient RA exposure with the dhrs3.L gene showing the strongest responses (Fig. 6D,E; Table 4). Since the DHRS3 enzyme preferentially reduces RAL back to ROL $[25,59,86]$, the dhrs3 CRISPants should 
exhibit enhanced RA signaling unless the RA network self regulation and robustness response compensates for this loss of activity [27]. Supporting the robustness scenario, the dhrs3 CRISPants alone had almost no effect on the RA responsive genes with the exception of the two hoxb1 homoeologs exhibiting a 1.5 to 7.5 increase in expression compared to control samples (not shown). Analysis at T0 of both dhrs3 CRISPants treated with RA treatment showed that these responses were not enhanced as expected, and the partial knockdown of one of the dhrs3 homoeologs resulted in reduced responses. In agreement with the loss of the loosely regulated homoeolog, these results show that the dhrs3.L CRISPants exhibit a stronger reduction in the RA response compared to knockdown of the dhrs3.S homoeolog (Fig. 7B and Supplemental Fig. S2B). Then, knockdown of the loosely regulated homoeolog achieves tighter regulation of the response.

While the T0 analysis supports the loss of the "noisier" gene to achieve tighter regulation of the response during the RA treatment, analysis of the full recovery kinetics compared to RA-only manipulated embryos provides information as to the effects of the homoeolog knockdown on the RA robustness response. Analysis of the same panel of RA-responsive genes showed that by about 1.5 hours into the recovery period (T1.5), the expression levels of the target genes tested in the dhrs3.L and dhrs3.S CRISPants was almost back to the same as the samples treated only with RA (Fig. 7D,F,H,J and Supplemental Fig. S2D,F,H,J). We could observe slight fluctuations in expression levels but in most instances, both CRISPants gave similar variations although the responses in the dhrs3.L tend to be lower than the RA-only samples, while the dhrs3.S CRISPants gave slightly enhanced responses. For multiple genes, at T0 we observed the up-regulation characteristic of the treatment before RA washing (Fig. 7F,H,J and Supplemental Fig. S2D,J). Also, at T0 and T1, CRISPants of the more tightly regulated homoeolog, dhrs3.S, exhibit larger fluctuations in expression of the RA responsive genes. Calculation of the regulation tightness score showed the opposed outcomes of the homoeolog-specific knockdown (Fig. 8B). The RA robustness response is enhanced by knockdown of the dhrs3.S homoeolog, while knockdown of dhrs3.L results in a reduced response. Analysis of the dhrs3 homoeologs identified the dhrs3.L 
gene as the one exhibiting enhanced responses to RA treatment and less tight regulation (Fig. 6D,E). Then, knockdown of the homoeolog exhibiting tighter regulation exposes the system to the homoeolog with the gene with the apparent looser regulation. Interestingly, within 1.5 hours in the recovery, the system appears to stabilize irrespective of the homoeolog manipulated even though both dhrs3 homoeologs take longer to reach normal expression levels. These observations suggest that the RA network robustness is capable of restoring normal signaling levels irrespective of the homoeolog knocked down.

\section{Conclusions}

The RA metabolic and signaling network is strongly dependent on the nutritional status and is influenced by the environment. Fluctuations in the RA signaling levels during embryogenesis can result in severe teratogenic outcomes. The preferential gene loss of the RA network components involved in the metabolism leading to RAL production suggests a selective pressure to achieve tighter regulation of the robustness response. Eliciting a RA robustness response by transient manipulation together with knockdown of specific genes support the suggestion that gene loss is linked to more efficient regulation of the network. Tighter network regulation might involve loss of homoeologs similarly regulated, or homoeologs with enhanced responses. While the allotetraploid condition of $X$. laevis is convenient to explore these genomic changes and their regulatory outcomes, in diploid organisms, besides gene duplications and deletions, mutation, addition and deletion of regulatory elements might take place to achieve the same outcome.

\section{Supplementary Materials:}

Supplementary Figure S1. Genomic sequence deterioration in the RA network CRISPants.

Supplemental Figure S2: RA responsiveness in RA network homoeolog-specific CRISPants. 


\section{Funding:}

This work was funded in part by grants from the United States-Israel Binational Science Foundation (2013422 and 2017199), The Israel Science Foundation (668/17), the Manitoba Liquor and Lotteries (RG-003-21), and the Wolfson Family Chair in Genetics to AF.

\section{Acknowledgments:}

We wish to thank Martin Blum and Tim Ott for introducing us to the manipulation of the Xenopus genome using CRISPR/Cas9. We also wish to thank Sally Moody and Graciela Pillemer for critically reading the manuscript.

\section{Author Contributions:}

Conceptualization, A.F., L.B.-K. and T.A.; Methodology, T.A.; Validation, T.A., L.B.-K. and A.S.; Formal Analysis, T.A., L.B.-K. and A.S.; Investigation, T.A., L.B.-K. and A.S.; Resources, X.X.; Data Curation, T.A., L.B.-K. and A.S.; Writing - Original Draft Preparation, A.F.; Writing - Review \& Editing, T.A., L.B.-K. and A.S.; Supervision, A.F.; Project Administration, A.F.; Funding Acquisition, A.F.",

\section{Institutional Review Board Statement:}

Experiments were performed after approval and under the supervision of the Institutional Animal Care and Use Committee (IACUC) of the Hebrew University (Ethics approval no. MD-17-15281-3).

\section{Informed Consent Statement:}

Not applicable

\section{Data Availability Statement:}

Data is contained within the article or supplementary material

\section{Conflicts of Interest:}


The authors declare no conflict of interest

\section{References:}

1. Metzler, M.A.; Sandell, L.L. Enzymatic metabolism of vitamin A in developing vertebrate embryos. Nutrients 2016, 8, pii: E812, doi:10.3390/nu8120812.

2. le Maire, A.; Bourguet, W. Retinoic acid receptors: structural basis for coregulator interaction and exchange. Subcell Biochem 2014, 70, 37-54, doi:10.1007/978-94-0179050-5_3.

3. Nolte, C.; De Kumar, B.; Krumlauf, R. Hox genes: Downstream “effectors" of retinoic acid signaling in vertebrate embryogenesis. Genesis 2019, 57, e23306, doi:10.1002/dvg.23306.

4. Draut, H.; Liebenstein, T.; Begemann, G. New Insights into the Control of Cell Fate Choices and Differentiation by Retinoic Acid in Cranial, Axial and Caudal Structures. Biomolecules 2019, 9, doi:10.3390/biom9120860.

5. Blaner, W.S. Vitamin A signaling and homeostasis in obesity, diabetes, and metabolic disorders. Pharmacol. Ther. 2019, 197, 153-178, doi:10.1016/j.pharmthera.2019.01.006.

6. Napoli, J.L. Post-natal all-trans-retinoic acid biosynthesis. Meth. Enzymol. 2020, 637, 27-54, doi:10.1016/bs.mie.2020.02.003.

7. Blaner, W.S.; Li, Y.; Brun, P.-J.; Yuen, J.J.; Lee, S.-A.; Clugston, R.D. Vitamin A absorption, storage and mobilization. Subcell Biochem 2016, 81, 95-125, doi:10.1007/978-94-024-0945-1_4.

8. Ghyselinck, N.B.; Duester, G. Retinoic acid signaling pathways. Development 2019, 146, doi:10.1242/dev.167502.

9. Kedishvili, N.Y. Retinoic acid synthesis and degradation. Subcell Biochem 2016, 81, 127-161, doi:10.1007/978-94-024-0945-1_5.

10. Shabtai, Y.; Fainsod, A. Competition between ethanol clearance and retinoic acid biosynthesis in the induction of fetal alcohol syndrome. Biochem. Cell Biol. 2018, 96, 148-160, doi:10.1139/bcb-2017-0132.

11. Collins, M.D.; Mao, G.E. Teratology of retinoids. Annu. Rev. Pharmacol. Toxicol. 1999, 39, 399-430, doi:10.1146/annurev.pharmtox.39.1.399.

12. Mark, M.; Ghyselinck, N.B.; Chambon, P. Function of retinoid nuclear receptors: lessons from genetic and pharmacological dissections of the retinoic acid signaling pathway during mouse embryogenesis. Annu. Rev. Pharmacol. Toxicol. 2006, 46, 451-480, doi:10.1146/annurev.pharmtox.46.120604.141156.

13. Fainsod, A.; Bendelac-Kapon, L.; Shabtai, Y. Fetal alcohol spectrum disorder: embryogenesis under reduced retinoic acid signaling conditions. Subcell Biochem 2020, 95, 197-225, doi:10.1007/978-3-030-42282-0_8. 
14. Fainsod, A.; Kot-Leibovich, H. Xenopus embryos to study fetal alcohol syndrome, a model for environmental teratogenesis. Biochem. Cell Biol. 2018, 96, 77-87, doi:10.1139/bcb-2017-0219.

15. Shabtai, Y.; Bendelac, L.; Jubran, H.; Hirschberg, J.; Fainsod, A. Acetaldehyde inhibits retinoic acid biosynthesis to mediate alcohol teratogenicity. Sci. Rep. 2018, 8, 347, doi:10.1038/s41598-017-18719-7.

16. Paganelli, A.; Gnazzo, V.; Acosta, H.; López, S.L.; Carrasco, A.E. Glyphosate-based herbicides produce teratogenic effects on vertebrates by impairing retinoic acid signaling. Chem. Res. Toxicol. 2010, 23, 1586-1595, doi:10.1021/tx1001749.

17. Dickinson, A.J.G.; Turner, S.D.; Wahl, S.; Kennedy, A.E.; Wyatt, B.H.; Howton, D.A. E-liquids and vanillin flavoring disrupts retinoic acid signaling and causes craniofacial defects in Xenopus embryos. Dev. Biol. 2022, 481, 14-29, doi:10.1016/j.ydbio.2021.09.004.

18. Niederreither, K.; McCaffery, P.; Dräger, U.C.; Chambon, P.; Dollé, P. Restricted expression and retinoic acid-induced downregulation of the retinaldehyde dehydrogenase type 2 (RALDH-2) gene during mouse development. Mech. Dev. 1997, 62, 67-78, doi:10.1016/S0925-4773(96)00653-3.

19. Pavez Loriè, E.; Chamcheu, J.C.; Vahlquist, A.; Törmä, H. Both all-trans retinoic acid and cytochrome P450 (CYP26) inhibitors affect the expression of vitamin A metabolizing enzymes and retinoid biomarkers in organotypic epidermis. Arch. Dermatol. Res. 2009, 301, 475-485, doi:10.1007/s00403-009-0937-7.

20. Moss, J.B.; Xavier-Neto, J.; Shapiro, M.D.; Nayeem, S.M.; McCaffery, P.; Dräger, U.C.; Rosenthal, N. Dynamic patterns of retinoic acid synthesis and response in the developing mammalian heart. Dev. Biol. 1998, 199, 55-71, doi:10.1006/dbio.1998.8911.

21. Hollemann, T.; Chen, Y.; Grunz, H.; Pieler, T. Regionalized metabolic activity establishes boundaries of retinoic acid signalling. EMBO J. 1998, 17, 7361-7372, doi:10.1093/emboj/17.24.7361.

22. Topletz, A.R.; Tripathy, S.; Foti, R.S.; Shimshoni, J.A.; Nelson, W.L.; Isoherranen, $\mathrm{N}$. Induction of CYP26A1 by metabolites of retinoic acid: evidence that CYP26A1 is an important enzyme in the elimination of active retinoids. Mol. Pharmacol. 2015, 87, 430-441, doi:10.1124/mol.114.096784.

23. Reijntjes, S.; Zile, M.H.; Maden, M. The expression of Stra6 and Rdh10 in the avian embryo and their contribution to the generation of retinoid signatures. Int. J. Dev. Biol. 2010, 54, 1267-1275, doi:10.1387/ijdb.093009sr.

24. Strate, I.; Min, T.H.; Iliev, D.; Pera, E.M. Retinol dehydrogenase 10 is a feedback regulator of retinoic acid signalling during axis formation and patterning of the central nervous system. Development 2009, 136, 461-472, doi:10.1242/dev.024901. 
25. Adams, M.K.; Belyaeva, O.V.; Wu, L.; Kedishvili, N.Y. The retinaldehyde reductase activity of DHRS3 is reciprocally activated by retinol dehydrogenase 10 to control retinoid homeostasis. J. Biol. Chem. 2014, 289, 14868-14880, doi:10.1074/jbc.M114.552257.

26. Kam, R.K.T.; Chen, Y.; Chan, S.-O.; Chan, W.-Y.; Dawid, I.B.; Zhao, H. Developmental expression of Xenopus short-chain dehydrogenase/reductase 3. Int. J. Dev. Biol. 2010, 54, 1355-1360, doi:10.1387/ijdb.092984rk.

27. Parihar, M.; Bendelac-Kapon, L.; Gur, M.; Abbou, T.; Belorkar, A.; Achanta, S.; Kinberg, K.; Vadigepalli, R.; Fainsod, A. Retinoic Acid Fluctuation Activates an Uneven, Direction-Dependent Network-Wide Robustness Response in Early Embryogenesis. Front. Cell Dev. Biol. 2021, 9, 747969, doi:10.3389/fcell.2021.747969.

28. Eldar, A.; Shilo, B.-Z.; Barkai, N. Elucidating mechanisms underlying robustness of morphogen gradients. Curr. Opin. Genet. Dev. 2004, 14, 435-439, doi:10.1016/j.gde.2004.06.009.

29. Ohno, S.; Wolf, U.; Atkin, N.B. Evolution from fish to mammals by gene duplication. Hereditas 1968, 59, 169-187, doi:10.1111/j.1601-5223.1968.tb02169.x.

30. Ohno, S. Gene duplication and the uniqueness of vertebrate genomes circa 19701999. Semin. Cell Dev. Biol. 1999, 10, 517-522, doi:10.1006/scdb.1999.0332.

31. MacKintosh, C.; Ferrier, D.E.K. Recent advances in understanding the roles of whole genome duplications in evolution. [version 2; peer review: 2 approved]. F1000Res. 2017, 6, 1623, doi:10.12688/f1000research.11792.2.

32. Session, A.M.; Uno, Y.; Kwon, T.; Chapman, J.A.; Toyoda, A.; Takahashi, S.; Fukui, A.; Hikosaka, A.; Suzuki, A.; Kondo, M.; van Heeringen, S.J.; Quigley, I.; Heinz, S.; Ogino, H.; Ochi, H.; Hellsten, U.; Lyons, J.B.; Simakov, O.; Putnam, N.; Stites, J.; Rokhsar, D.S. Genome evolution in the allotetraploid frog Xenopus laevis. Nature 2016, 538, 336-343, doi:10.1038/nature19840.

33. Wolf, Y.I.; Koonin, E.V. Genome reduction as the dominant mode of evolution. Bioessays 2013, 35, 829-837, doi:10.1002/bies.201300037.

34. Newton, M.S.; Arcus, V.L.; Gerth, M.L.; Patrick, W.M. Enzyme evolution: innovation is easy, optimization is complicated. Curr. Opin. Struct. Biol. 2018, 48, 110-116, doi:10.1016/j.sbi.2017.11.007.

35. Albalat, R.; Cañestro, C. Evolution by gene loss. Nat. Rev. Genet. 2016, 17, 379-391, doi:10.1038/nrg.2016.39.

36. Morin, R.D.; Chang, E.; Petrescu, A.; Liao, N.; Griffith, M.; Chow, W.; Kirkpatrick, R.; Butterfield, Y.S.; Young, A.C.; Stott, J.; Barber, S.; Babakaiff, R.; Dickson, M.C.; Matsuo, C.; Wong, D.; Yang, G.S.; Smailus, D.E.; Wetherby, K.D.; Kwong, P.N.; Grimwood, J.; Holt, R.A. Sequencing and analysis of 10,967 full-length cDNA clones from Xenopus laevis and Xenopus tropicalis reveals post-tetraploidization 
transcriptome remodeling. Genome Res. 2006, 16, 796-803, doi:10.1101/gr.4871006.

37. Hellsten, U.; Harland, R.M.; Gilchrist, M.J.; Hendrix, D.; Jurka, J.; Kapitonov, V.;

Ovcharenko, I.; Putnam, N.H.; Shu, S.; Taher, L.; Blitz, I.L.; Blumberg, B.;

Dichmann, D.S.; Dubchak, I.; Amaya, E.; Detter, J.C.; Fletcher, R.; Gerhard, D.S.;

Goodstein, D.; Graves, T.; Rokhsar, D.S. The genome of the Western clawed frog

Xenopus tropicalis. Science 2010, 328, 633-636, doi:10.1126/science.1183670.

38. Sémon, M.; Wolfe, K.H. Preferential subfunctionalization of slow-evolving genes after allopolyploidization in Xenopus laevis. Proc Natl Acad Sci USA 2008, 105, 8333-8338, doi:10.1073/pnas.0708705105.

39. Chain, F.J.J.; Dushoff, J.; Evans, B.J. The odds of duplicate gene persistence after polyploidization. BMC Genomics 2011, 12, 599, doi:10.1186/1471-2164-12-599.

40. Watanabe, M.; Yasuoka, Y.; Mawaribuchi, S.; Kuretani, A.; Ito, M.; Kondo, M.; Ochi, H.; Ogino, H.; Fukui, A.; Taira, M.; Kinoshita, T. Conservatism and variability of gene expression profiles among homeologous transcription factors in Xenopus laevis. Dev. Biol. 2017, 426, 301-324, doi:10.1016/j.ydbio.2016.09.017.

41. Michiue, T.; Yamamoto, T.; Yasuoka, Y.; Goto, T.; Ikeda, T.; Nagura, K.; Nakayama, T.; Taira, M.; Kinoshita, T. High variability of expression profiles of homeologous genes for Wnt, Hh, Notch, and Hippo signaling pathways in Xenopus laevis. Dev. Biol. 2017, 426, 270-290, doi:10.1016/j.ydbio.2016.12.006.

42. Suzuki, A.; Yoshida, H.; van Heeringen, S.J.; Takebayashi-Suzuki, K.; Veenstra, G.J.C.; Taira, M. Genomic organization and modulation of gene expression of the TGF-• and FGF pathways in the allotetraploid frog Xenopus laevis. Dev. Biol. 2017, 426, 336-359, doi:10.1016/j.ydbio.2016.09.016.

43. Nieuwkoop, P.D.; Faber, J. Normal table of Xenopus laevis (Daudin): A systematical and chronological survey of the development from the fertilized egg till the end of metamorphosis.; North-Holland Publishing Company: Amsterdam, 1967; p. 260;.

44. Nenni, M.J.; Fisher, M.E.; James-Zorn, C.; Pells, T.J.; Ponferrada, V.; Chu, S.; Fortriede, J.D.; Burns, K.A.; Wang, Y.; Lotay, V.S.; Wang, D.Z.; Segerdell, E.; Chaturvedi, P.; Karimi, K.; Vize, P.D.; Zorn, A.M. Xenbase: facilitating the use of xenopus to model human disease. Front. Physiol. 2019, 10, 154, doi:10.3389/fphys.2019.00154.

45. Naito, Y.; Hino, K.; Bono, H.; Ui-Tei, K. CRISPRdirect: software for designing CRISPR/Cas guide RNA with reduced off-target sites. Bioinformatics 2015, 31, 1120-1123, doi:10.1093/bioinformatics/btu743.

46. Moreno-Mateos, M.A.; Vejnar, C.E.; Beaudoin, J.-D.; Fernandez, J.P.; Mis, E.K.; Khokha, M.K.; Giraldez, A.J. CRISPRscan: designing highly efficient sgRNAs for CRISPR-Cas9 targeting in vivo. Nat. Methods 2015, 12, 982-988, doi:10.1038/nmeth.3543. 
47. Naert, T.; Tulkens, D.; Edwards, N.A.; Carron, M.; Shaidani, N.-I.; Wlizla, M.; Boel, A.; Demuynck, S.; Horb, M.E.; Coucke, P.; Willaert, A.; Zorn, A.M.; Vleminckx, K. Maximizing CRISPR/Cas9 phenotype penetrance applying predictive modeling of editing outcomes in Xenopus and zebrafish embryos. Sci. Rep. 2020, 10, 14662, doi:10.1038/s41598-020-71412-0.

48. Shen, M.W.; Arbab, M.; Hsu, J.Y.; Worstell, D.; Culbertson, S.J.; Krabbe, O.; Cassa, C.A.; Liu, D.R.; Gifford, D.K.; Sherwood, R.I. Predictable and precise template-free CRISPR editing of pathogenic variants. Nature 2018, 563, 646-651, doi:10.1038/s41586-018-0686-x.

49. Hoshijima, K.; Jurynec, M.J.; Klatt Shaw, D.; Jacobi, A.M.; Behlke, M.A.; Grunwald, D.J. Highly Efficient CRISPR-Cas9-Based Methods for Generating Deletion Mutations and F0 Embryos that Lack Gene Function in Zebrafish. Dev. Cell 2019, 51, 645-657.e4, doi:10.1016/j.devcel.2019.10.004.

50. Brinkman, E.K.; Chen, T.; Amendola, M.; van Steensel, B. Easy quantitative assessment of genome editing by sequence trace decomposition. Nucleic Acids Res. 2014, 42, e168, doi:10.1093/nar/gku936.

51. Hsiau, T.; Maures, T.; Waite, K.; Yang, J.; Kelso, R.; Holden, K.; Stoner, R. Inference of CRISPR Edits from Sanger Trace Data. BioRxiv 2018, doi:10.1101/251082.

52. Kanehisa, M.; Sato, Y.; Kawashima, M. KEGG mapping tools for uncovering hidden features in biological data. Protein Sci. 2021, doi:10.1002/pro.4172.

53. Yanai, I.; Peshkin, L.; Jorgensen, P.; Kirschner, M.W. Mapping gene expression in two Xenopus species: evolutionary constraints and developmental flexibility. Dev. Cell 2011, 20, 483-496, doi:10.1016/j.devcel.2011.03.015.

54. Savova, V.; Pearl, E.J.; Boke, E.; Nag, A.; Adzhubei, I.; Horb, M.E.; Peshkin, L. Transcriptomic insights into genetic diversity of protein-coding genes in $\mathrm{X}$. laevis. Dev. Biol. 2017, 424, 181-188, doi:10.1016/j.ydbio.2017.02.019.

55. Parihar, M.; Bendelac-Kapon, L.; Gur, M.; Abbou, T.; Belorkar, A.; Achanta, S.; Kinberg, K.; Vadigepalli, R.; Fainsod, A. Retinoic Acid Fluctuation Activates an Uneven, Direction-Dependent Network-Wide Robustness Response in Early Embryogenesis. Front. Cell Dev. Biol. 2021, 9, 747969, doi:10.3389/fcell.2021.747969.

56. Shannon, S.R.; Moise, A.R.; Trainor, P.A. New insights and changing paradigms in the regulation of vitamin A metabolism in development. Wiley Interdiscip. Rev. Dev. Biol. 2017, 6, doi:10.1002/wdev.264.

57. Belyaeva, O.V.; Adams, M.K.; Wu, L.; Kedishvili, N.Y. The antagonistically bifunctional retinoid oxidoreductase complex is required for maintenance of alltrans-retinoic acid homeostasis. J. Biol. Chem. 2017, 292, 5884-5897, doi:10.1074/jbc.M117.776914.

58. Shabtai, Y.; Shukrun, N.; Fainsod, A. ADHFe1: a novel enzyme involved in 
retinoic acid-dependent Hox activation. Int. J. Dev. Biol. 2017, 61, 303-310, doi:10.1387/ijdb.160252af.

59. Billings, S.E.; Pierzchalski, K.; Butler Tjaden, N.E.; Pang, X.-Y.; Trainor, P.A.; Kane, M.A.; Moise, A.R. The retinaldehyde reductase DHRS3 is essential for preventing the formation of excess retinoic acid during embryonic development. FASEB J. 2013, 27, 4877-4889, doi:10.1096/fj.13-227967.

60. Feng, L.; Hernandez, R.E.; Waxman, J.S.; Yelon, D.; Moens, C.B. Dhrs3a regulates retinoic acid biosynthesis through a feedback inhibition mechanism. Dev. Biol. 2010, 338, 1-14, doi:10.1016/j.ydbio.2009.10.029.

61. Porté, S.; Xavier Ruiz, F.; Giménez, J.; Molist, I.; Alvarez, S.; Domínguez, M.; Alvarez, R.; de Lera, A.R.; Parés, X.; Farrés, J. Aldo-keto reductases in retinoid metabolism: search for substrate specificity and inhibitor selectivity. Chem. Biol. Interact. 2013, 202, 186-194, doi:10.1016/j.cbi.2012.11.014.

62. Cui, J.; Michaille, J.-J.; Jiang, W.; Zile, M.H. Retinoid receptors and vitamin A deficiency: differential patterns of transcription during early avian development and the rapid induction of RARs by retinoic acid. Dev. Biol. 2003, 260, 496-511.

63. Lohnes, D.; Mark, M.; Mendelsohn, C.; Dollé, P.; Decimo, D.; LeMeur, M.; Dierich, A.; Gorry, P.; Chambon, P. Developmental roles of the retinoic acid receptors. J. Steroid Biochem. Mol. Biol. 1995, 53, 475-486, doi:10.1016/0960-0760(95)00094-g.

64. Janesick, A.; Wu, S.C.; Blumberg, B. Retinoic acid signaling and neuronal differentiation. Cell. Mol. Life Sci. 2015, 72, 1559-1576, doi:10.1007/s00018-0141815-9.

65. De Bosscher, K.; Desmet, S.J.; Clarisse, D.; Estébanez-Perpiña, E.; Brunsveld, L. Nuclear receptor crosstalk - defining the mechanisms for therapeutic innovation. Nat. Rev. Endocrinol. 2020, 16, 363-377, doi:10.1038/s41574-020-0349-5.

66. Evans, R.M.; Mangelsdorf, D.J. Nuclear receptors, RXR, and the big bang. Cell 2014, 157, 255-266, doi:10.1016/j.cell.2014.03.012.

67. Niederreither, K.; Subbarayan, V.; Dollé, P.; Chambon, P. Embryonic retinoic acid synthesis is essential for early mouse post-implantation development. Nat. Genet. 1999, 21, 444-448, doi:10.1038/7788.

68. Begemann, G.; Schilling, T.F.; Rauch, G.J.; Geisler, R.; Ingham, P.W. The zebrafish neckless mutation reveals a requirement for raldh2 in mesodermal signals that pattern the hindbrain. Development 2001, 128, 3081-3094.

69. Grandel, H.; Lun, K.; Rauch, G.-J.; Rhinn, M.; Piotrowski, T.; Houart, C.; Sordino, P.; Küchler, A.M.; Schulte-Merker, S.; Geisler, R.; Holder, N.; Wilson, S.W.; Brand, $M$. Retinoic acid signalling in the zebrafish embryo is necessary during presegmentation stages to pattern the anterior-posterior axis of the CNS and to induce a pectoral fin bud. Development 2002, 129, 2851-2865. 
70. Chen, Y.; Pollet, N.; Niehrs, C.; Pieler, T. Increased XRALDH2 activity has a posteriorizing effect on the central nervous system of Xenopus embryos. Mech. Dev. 2001, 101, 91-103, doi:10.1016/S0925-4773(00)00558-X.

71. Durston, A.J.; Timmermans, J.P.; Hage, W.J.; Hendriks, H.F.; de Vries, N.J.; Heideveld, M.; Nieuwkoop, P.D. Retinoic acid causes an anteroposterior transformation in the developing central nervous system. Nature 1989, 340, 140144, doi:10.1038/340140a0.

72. Schuh, T.J.; Hall, B.L.; Kraft, J.C.; Privalsky, M.L.; Kimelman, D. v-erbA and citral reduce the teratogenic effects of all-trans retinoic acid and retinol, respectively, in Xenopus embryogenesis. Development 1993, 119, 785-798.

73. Chen, Y.; Huang, L.; Solursh, M. A concentration gradient of retinoids in the early Xenopus laevis embryo. Dev. Biol. 1994, 161, 70-76, doi:10.1006/dbio.1994.1008.

74. Kraft, J.C.; Schuh, T.; Juchau, M.; Kimelman, D. The retinoid X receptor ligand, 9cis-retinoic acid, is a potential regulator of early Xenopus development. Proc Natl Acad Sci USA 1994, 91, 3067-3071.

75. Creech Kraft, J.; Schuh, T.; Juchau, M.R.; Kimelman, D. Temporal distribution, localization and metabolism of all-trans-retinol, didehydroretinol and all-transretinal during Xenopus development. Biochem. J. 1994, 301 ( Pt 1), 111-119.

76. Creech Kraft, J.; Kimelman, D.; Juchau, M.R. Xenopus laevis: a model system for the study of embryonic retinoid metabolism. II. Embryonic metabolism of alltrans-3,4-didehydroretinol to all-trans-3,4-didehydroretinoic acid. Drug Metab. Dispos. 1995, 23, 83-89.

77. Kraft, J.C.; Kimelman, D.; Juchau, M.R. Xenopus laevis: a model system for the study of embryonic retinoid metabolism. I. Embryonic metabolism of 9-cis- and all-trans-retinals and retinols to their corresponding acid forms. Drug Metab. Dispos. 1995, 23, 72-82.

78. Dobbs-McAuliffe, B.; Zhao, Q.; Linney, E. Feedback mechanisms regulate retinoic acid production and degradation in the zebrafish embryo. Mech. Dev. 2004, 121, 339-350, doi:10.1016/j.mod.2004.02.008.

79. Sive, H.L.; Draper, B.W.; Harland, R.M.; Weintraub, H. Identification of a retinoic acid-sensitive period during primary axis formation in Xenopus laevis. Genes Dev. 1990, 4, 932-942, doi:10.1101/gad.4.6.932.

80. Kessel, M.; Gruss, P. Homeotic transformations of murine vertebrae and concomitant alteration of Hox codes induced by retinoic acid. Cell 1991, 67, 89-104, doi:10.1016/0092-8674(91)90574-i.

81. Papalopulu, N.; Clarke, J.D.; Bradley, L.; Wilkinson, D.; Krumlauf, R.; Holder, N. Retinoic acid causes abnormal development and segmental patterning of the anterior hindbrain in Xenopus embryos. Development 1991, 113, 1145-1158. 
82. Corcoran, J.; So, P.L.; Maden, M. Absence of retinoids can induce motoneuron disease in the adult rat and a retinoid defect is present in motoneuron disease patients. J. Cell Sci. 2002, 115, 4735-4741.

83. Adams, M.K.; Lee, S.-A.; Belyaeva, O.V.; Wu, L.; Kedishvili, N.Y. Characterization of human short chain dehydrogenase/reductase SDR16C family members related to retinol dehydrogenase 10. Chem. Biol. Interact. 2017, 276, 88-94, doi:10.1016/j.cbi.2016.10.019.

84. Belyaeva, O.V.; Lee, S.-A.; Adams, M.K.; Chang, C.; Kedishvili, N.Y. Short chain dehydrogenase/reductase rdhe 2 is a novel retinol dehydrogenase essential for frog embryonic development. J. Biol. Chem. 2012, 287, 9061-9071, doi:10.1074/jbc.M111.336727.

85. Belyaeva, O.V.; Kedishvili, N.Y. Human pancreas protein 2 (PAN2) has a retinal reductase activity and is ubiquitously expressed in human tissues. FEBS Lett. 2002, 531, 489-493, doi:10.1016/s0014-5793(02)03588-3.

86. Kam, R.K.T.; Shi, W.; Chan, S.O.; Chen, Y.; Xu, G.; Lau, C.B.-S.; Fung, K.P.; Chan, W.Y.; Zhao, H. Dhrs3 protein attenuates retinoic acid signaling and is required for early embryonic patterning. J. Biol. Chem. 2013, 288, 31477-31487, doi:10.1074/jbc.M113.514984. 
Table 1. Sequences for $q P C R$ and genomic DNA amplification primers and sgRNAs

\begin{tabular}{|c|c|c|}
\hline Gene & Forward primer & Reverse primer \\
\hline \multicolumn{3}{|c|}{ qPCR analysis } \\
\hline cyp26a1.L & TCGAGGTTCGGCTTCATC & CGGCACAATTCCACAACA \\
\hline hoxb1.L & TTGCCCCAGTGCCAATGAC & TCССССТССАACAACAAACC \\
\hline hoxd1.L/S & TTCTTGCGGGGATGTTTT & CCGACTGGCATAAAGGAA \\
\hline hoxa1.L & CCGCTCACTATATCCACCATTC & TGGCAGGAGAACGACAAAC \\
\hline hoxa1.S & TGACTGTAAACACCTAGTAAATGAAG & AATTAATGAGATGATGGAATGGTAAA \\
\hline hoxb1.S & GTGGCTGCGATCTCTACTCTC & CCAACTTCACGACCAAACAA \\
\hline hoxb4.S & CCAAGGATCTGTGCGTCAA & GCAGGATGGAGGCGAACT \\
\hline hoxa2.L/S & GGAGATTGCAGCCCTGTT & GGGTTTGCCTCTTGTGTTTC \\
\hline sdr16c5.L & TTTGTGGTTCCTTCCCTCTC & GTGCCATCAGTCTCCCTATACC \\
\hline rdh14.L & TGCCCGTACACAAAGACAGA & GAGACCAAGGAGGTGGTGAG \\
\hline hoxa1 & CCGCTCACTATATCCACCATTC & TGGCAGGAGAACGACAAAC \\
\hline hoxb1 & TTGCCCCAGTGCCAATGAC & TCССССТССАACAACAAACC \\
\hline hoxb4 & CCAAGGATCTGTGCGTCAA & GCAGGATGGAGGCGAACT \\
\hline dhrs3.L & CAGGCGCAAGAAATCCTAAG & CAAAGGCCACGTTCAAGGAT \\
\hline dhrs3.S & TGCAGATGGTATTGTCCCTTC & TCCTTAGCGAGGTGTCGG \\
\hline rdh10.L & CGTCTCTTTGCCCTGGAGTTT & CACCATCTCCGCCGTCTC \\
\hline rdh10.S & TTGCTTGGCCTGTAGAAGAGA & TGCATGGCGAAATAGGAGTAG \\
\hline s/c35b1.L & CGCATTTCCAAACAGGCTCC & CAAGAAGTCCCAGAGCTCGC \\
\hline \multicolumn{3}{|c|}{ Genomic nested PCR } \\
\hline \multicolumn{3}{|c|}{ Outer genomic PCR } \\
\hline dhrs3.L & TGACTGTAAGAATAGCCGCGT & AGCGGGCAGACAAGACAAAT \\
\hline dhrs3.S & ACCGCTATAGAACCACAGTCG & GAAACACTTCATTCCTTTTAGTGGA \\
\hline rdh10.L & TAAGTTGGCAGCGGTTTGGG & GAGAGACCCCACATAACTCAGC \\
\hline rdh10.S & TCCAGAGCGAAAATCTGACGA & TCCCATGGTCATGAAACTCCTCAG \\
\hline sdr16c5 & ACTGTCTTCATAGTCGAGCCC & TGGTCCGAATAGAAAATCTGGG \\
\hline rdh14 & CACACCAAACATGGCGACTT & TGAAGGGCGTTGACTGTGAC \\
\hline \multicolumn{3}{|c|}{ Inner genomic PCR } \\
\hline sdr16c5 & GTTCCACCTTTCTGTCAATGCTC & AGCATTTGTCCTCAGCGTTTT \\
\hline rdh14 & GAGTAACAGCGTCAGAGCCG & TGAAGGGCGTTGACTGTGAC \\
\hline dhrs3.L & GAGTCTCAGCACAGGGCAAA & TCAAAGGGTGACAGGGAACG \\
\hline dhrs3.S & CACAGTCGTTGGCTTGAGTG & CCTTTCACTTTTTGCAGGATTCA \\
\hline rdh10.L & CGCACGGAACTTACTGTCCA & TTGGACCCTGGAGCTGTACT \\
\hline rdh10.s & TCCAGAGCGAAAATCTGACGA & GAGTGGCAGTAGAGTGAAGTCAG \\
\hline \multicolumn{3}{|c|}{ sgRNA (crRNA) } \\
\hline sdr16c5 & AAACAAAGAGACCTGTAGAC & \\
\hline rdh14 & GTCTGTCCGGCGATTCTGTC & \\
\hline dhrs3.L & CTTATTGGGCATCAGCAAGT & \\
\hline dhrs3.S & GTCCTAGTGTGTTAATGTGT & \\
\hline rdh10.L & GCGCAGCAGCCACTTGCCCG & \\
\hline rdh10.S & AGGCGGAGGACTCTGCGCGG & \\
\hline
\end{tabular}


Table 2. Singleton distribution in Xenopus laevis metabolic and signaling pathways.

\begin{tabular}{|c|c|c|c|}
\hline Pathway & $\begin{array}{l}\text { Total } \\
\text { genes }\end{array}$ & Singletons & $\begin{array}{c}\% \\
\text { Singletons }\end{array}$ \\
\hline \multicolumn{4}{|l|}{ High singleton } \\
\hline Vitamin D from 7-dehydrocholesterol $^{1}$ & 9 & 6 & $66.7 \%$ \\
\hline RA up to $\mathrm{RAL}^{1}$ & 28 & 21 & $75 \%$ \\
\hline Folic acid metabolism ${ }^{1}$ & 27 & 19 & $70.4 \%$ \\
\hline DNA repair & 57 & 45 & $78.9 \%$ \\
\hline \multicolumn{4}{|l|}{ Average genome singletons } \\
\hline De novo Purine biosynthesis ${ }^{1}$ & 15 & 7 & $46.7 \%$ \\
\hline Thyroid hormone synhesis $^{1}$ & 52 & 23 & $44.2 \%$ \\
\hline Protein-coding ${ }^{2}$ & $>13781$ & & $43.6 \%$ \\
\hline RA signaling metabolism and signaling & 47 & 22 & $46.8 \%$ \\
\hline Vitamin D incl. 7-dehydrocholesterol $^{1}$ & 21 & 8 & $38.1 \%$ \\
\hline \multicolumn{4}{|l|}{ Suppressed singletons } \\
\hline Glycolysis/Gluconeogenesis/Krebs cycle $^{1}$ & 44 & 9 & $20.5 \%$ \\
\hline Notch $^{3}$ & 48 & 8 & $16.7 \%$ \\
\hline MicroRNAs $^{2}$ & 180 & 24 & $13.3 \%$ \\
\hline Transcription Factors $^{4}$ & 218 & 28 & $12.8 \%$ \\
\hline $\mathrm{Wnt}^{3}$ & 108 & 13 & $12 \%$ \\
\hline $\mathrm{Hippo}^{3}$ & 48 & 5 & $10.4 \%$ \\
\hline $\mathrm{BMP} / \mathrm{TGF}^{5}$ & 126 & 13 & $10.3 \%$ \\
\hline $\mathrm{RA}$ from $\mathrm{RAL}^{1}$ & 19 & 1 & $5.2 \%$ \\
\hline FGF $^{5}$ & 60 & 3 & $5 \%$ \\
\hline cis-regulatory elements (non-coding) ${ }^{2}$ & 550 & 9 & $1.6 \%$ \\
\hline $\mathrm{Hh}^{3}$ & 18 & 0 & $0 \%$ \\
\hline $\mathrm{HSPG}^{3}$ & 16 & 0 & $0 \%$ \\
\hline TLE $^{3}$ & 4 & 0 & $0 \%$ \\
\hline
\end{tabular}

${ }^{1}$ Data from KEGG, this work; ${ }^{2}$ Session et al., 2016; ${ }^{3}$ Michiue et al., 2017; ${ }^{4}$ Watanabe et al., 2017; ${ }^{5}$ Suzuki et al., 2017. 
bioRxiv preprint doi: https://doi.org/10.1101/2022.01.04.474867; this version posted January 4, 2022. The copyright holder for this preprint (which was not certified by peer review) is the author/funder, who has granted bioRxiv a license to display the preprint in perpetuity. It is made available under aCC-BY-NC-ND 4.0 International license.

Table 3. Genomic changes in the generation of RA network singletons.

\begin{tabular}{|c|c|c|c|c|c|c|c|c|c|}
\hline \multirow[t]{2}{*}{ Name } & \multirow[t]{2}{*}{$\mathrm{L} / \mathrm{S}^{1}$} & \multirow{2}{*}{$\begin{array}{c}\text { Transcribed } \\
\text { region length } \\
\text { (bp) }\end{array}$} & \multirow[t]{2}{*}{$\begin{array}{c}\text { Flanking } \\
\text { genes }^{2}\end{array}$} & \multirow[t]{2}{*}{$\begin{array}{l}\text { Genes in the } \mathrm{L} \\
\text { genomic region }\end{array}$} & \multirow[t]{2}{*}{$\begin{array}{l}\text { Genes in the } \mathrm{S} \\
\text { genomic region }\end{array}$} & \multicolumn{2}{|c|}{\begin{tabular}{|c|}
$\begin{array}{c}\text { Genomic length } \\
\text { (bp) }\end{array}$ \\
\end{tabular}} & \multirow{2}{*}{$\begin{array}{c}\text { Length } \\
\text { difference } \\
(\mathrm{Kb})\end{array}$} & \multirow[t]{2}{*}{$\begin{array}{c}\text { Deletion } \\
\text { type }\end{array}$} \\
\hline & & & & & & $\mathbf{L}$ & $\bar{S}$ & & \\
\hline \multicolumn{10}{|c|}{$\begin{array}{l}\text { Producers } 1 \\
\end{array}$} \\
\hline sdr16c5 & $6 \mathrm{~L}$ & 18,952 & $\begin{array}{l}\text { plag1- } \\
\text { penk }\end{array}$ & chchd7, sdr16c5 & - & 89,214 & 79,69 & 9.5 & Restricted \\
\hline $\begin{array}{l}\text { adh7 } \\
\text { adh4 } \\
\text { adh1b }\end{array}$ & $\begin{array}{l}1 \mathrm{~S} \\
1 \mathrm{~L} \\
1 \mathrm{~L}\end{array}$ & $\begin{array}{c}9,948 \\
13,797 \\
18,159\end{array}$ & $\begin{array}{l}\text { dapp1- } \\
\text { metap1 }\end{array}$ & $\begin{array}{c}\text { LOC108710849, } \\
\text { MGC83376, adh1b, } \\
\text { adh4, adh1-a, } \\
\text { LOC108719623, adh5 }\end{array}$ & $\begin{array}{l}\text { LOC398377, } \\
\text { LOC108706741, } \\
\text { adh1a, adh7 }\end{array}$ & 277,881 & \begin{tabular}{|l|}
196,627 \\
\end{tabular} & 81.3 & Complex \\
\hline$r d h 16$ & $2 \mathrm{~L}$ & 11,580 & $\begin{array}{l}\text { rdh7.2- } \\
\text { gpr182 }\end{array}$ & $\begin{array}{l}\boldsymbol{r d h 1 6}, \mathrm{XB5807236} \\
\text { rdh7, LOC 108708580, } \\
\text { rdh9, hsd17b6, } \\
\text { LOC10870858 }\end{array}$ & - & 116,911 & 14,959 & 102.0 & Large \\
\hline dhrs9 & 9_10L & 9,073 & $\begin{array}{l}\text { stk39- } \\
\text { klh/41 }\end{array}$ & $\begin{array}{c}\text { dhrs9, LOC108701361, } \\
\text { nostrin, LOC108701845, } \\
\text { XB5957220, Irp2, } \\
\text { LOC108701363, } \\
\text { LOC108701365, } \\
\text { LOC108701364, bbs5 }\end{array}$ & $\begin{array}{c}\text { LOC108702983, } \\
a b c b 11.2, \\
\text { LOC108702985, } \\
\text { LOC108702267 }\end{array}$ & 521,928 & 283,492 & 238.4 & Complex \\
\hline \multicolumn{10}{|c|}{ Suppressors } \\
\hline adhFe1 & $6 S$ & 19,503 & rrs1-myb/1 & LOC108718816, vxn & $\begin{array}{c}\text { LOC121395160 } \\
\text { adhFe1 }\end{array}$ & 63,4 & 63,3 & 0.1 & Restricted \\
\hline rdh13 & $5 \mathrm{~L}$ & 10,266 & $\begin{array}{l}\text { slc30a6- } \\
\text { sos } 1\end{array}$ & rdh13 & - & 42,225 & 5,878 & 36.3 & Restricted \\
\hline rdh14 & $5 \mathrm{~L}$ & 4,946 & $\begin{array}{l}\text { kcns3- } \\
\text { osr1 }\end{array}$ & $\begin{array}{c}\text { LOC121393845, } \\
\text { LOC108717194, } \\
\text { LOC121393566, } \boldsymbol{r d h} \mathbf{1 4}\end{array}$ & - & 609,595 & \begin{tabular}{|l|}
488,124 \\
\end{tabular} & 121.5 & Large \\
\hline \multicolumn{10}{|c|}{$\begin{array}{l}1 \\
\text { Producers } 3\end{array}$} \\
\hline$b c 01$ & $4 \mathrm{~L}$ & 20,949 & gan-cenpn & $\begin{array}{c}\text { bco1, LOC108714031, } \\
\text { LOC108714032, gcsh, } \\
\text { LOC108714033, } \\
\text { LOC108714034, } \\
\text { LOC108714035, cdk10, } \\
\text { LOC121403143, } \\
\text { LOC121403144, } \\
\text { LOC108714036, } \\
\text { LOC108714037, atmin }\end{array}$ & $\begin{array}{l}\text { LOC108708941, } \\
\text { LOC108715382, } \\
\text { LOC108715380, } \\
\text { LOC108705941 }\end{array}$ & 306,957 & 114,993 & 192.0 & Large \\
\hline $\begin{array}{l}b c o 2 \\
b c o 2 l\end{array}$ & $\begin{array}{l}2 \mathrm{~L} \\
2 \mathrm{~L}\end{array}$ & $\begin{array}{l}14,883 \\
38,972\end{array}$ & $\begin{array}{l}\text { urpta-1- } \\
\text { zbtb16 }\end{array}$ & $\begin{array}{c}\text { sfxn4, bco2, bco2l, } \\
\text { LOC121395554, } \\
\text { LOC108697004, nnmt, } \\
\text { LOC108695837, } \\
\text { LOC108696501, } \\
\text { LOC 108697006, } \\
\text { LOC108696502, } \\
\text { LOC121395555, } \\
\text { LOC108696503, } \\
\text { LOC108697007, } \\
\text { LOC121395556, } \\
\text { LOC } 108696506\end{array}$ & LOC108697615 & 611,546 & \begin{tabular}{|l|}
200,702 \\
\end{tabular} & 410.8 & Large \\
\hline
\end{tabular}

${ }^{1}$ Chromosomal location. ${ }^{2}$ Flanking genes represent the conserved genes at the ends modified genomic region.

${ }^{3}$ Distance between the conserved flanking genes 
Table 4. Regulation tightness score for the RA network homoeologs and singletons

\begin{tabular}{|l|c|c|}
\hline \multirow{2}{*}{ Gene } & \multicolumn{2}{|c|}{$\sum \Delta$ score $^{1}$} \\
\cline { 2 - 3 } & 10nM RA & 25nM RA \\
\hline Suppressors \\
\hline dhrs3.L & 28.1 & 29.4 \\
\hline dhrs3.S & 15.5 & 16.4 \\
\hline rdh14.L & 5.2 & 5.1 \\
\hline Producers 1 \\
\hline rdh10.L & 4.9 & 5.2 \\
\hline rdh10.S & 4.8 & 4.6 \\
\hline sdr16c5 & 5.8 & 5.3 \\
\hline Producers 2 & \multicolumn{2}{|}{} \\
\hline aldh1a2.L & 4.3 & 4.4 \\
\hline aldh1a2.S & 4.9 & 5.2 \\
\hline aldh1a3.L & 10.0 & 6.4 \\
\hline aldh1a3.S & 7.8 & 5.5 \\
\hline
\end{tabular}

${ }^{1}$ Regulation tightness score 


\section{Figure Legends}

Figure 1. Evolutionary conservation of the RA metabolic and gene-regulatory network genes in Xenopus laevis. Composition of the RA metabolic and generegulatory network in the Xenopus laevis genome based on KEGG and Xenbase database analysis and literature searches [44,52]. Expression of the RA network components during gastrula stages was determined from our own and published transcriptomic datasets. The relative expression shown (blue shades) during gastrula stages is based on Session et al., [32]. Dark blue, •10 TPM; mid blue, >0.5-<10 TPM; light blue, •0.5 TPM; white, no data in the transcriptomic dataset. The homoeolog/singleton status of each gene is marked ( $\mathrm{L}$ and/or S). The relative expression levels between homoeologs are summarized: =, similar expression levels; <, 3-6 fold difference; <<, more than 6 fold difference. Asterisks indicate whether temporal expression patterns of the homeologs are similar (no asterisk), partially divergent $\left({ }^{*}\right)$, or highly divergent $\left.{ }^{* *}\right)$.

\section{Figure 2. Homoeolog and singleton status of genes involved in Vitamin D}

metabolism and signaling. KEGG analysis of the vitamin D metabolic and signaling network identified 21 genes in the $X$. laevis genome. The homoeolog/singleton status of each gene is marked ( $\mathrm{L}$ and/or S). In the metabolic part of the pathway leading to cholesterol production (above the red dotted line), the pathway runs in parallel from lenosterol and dehydrolanosterol. The relative expression levels between homoeologs are summarized: $=$, similar expression levels; $<$, 3-6 fold difference; $<<$, more than 6 fold difference. Asterisks indicate whether temporal expression patterns of the homeologs are similar (no asterisk), partially divergent $\left({ }^{*}\right)$, or highly divergent $\left({ }^{* *}\right)$.

Figure 3. Genomic rearrangements involving RA network genes. Schematic examples of the types of genomic deletions and rearrangements observed in the deletion of homoeologs. The gene conserved, i.e., singleton, is marked in green. The flanking genes selected to determine the interval that was deleted are marked in red. Additional genes or putative coding sequences within the regions are marked in gray. (A) Generation of 
the $s d r 16 c 5$.L singleton apparently involved the deletion of a small genomic region on chromosome 6S. (B) The deletion to create the rdh16.L singleton involved deleting about $100 \mathrm{~Kb}$ on chromosome $2 \mathrm{~S}$ including multiple genes. (C) The genomic reorganization and deletion on chromosome 1 created the adh7.S singleton on chromosome $1 S$ and singletons for adh1.L, adh4.L, and adh5.L on chromosome 1L.

Figure 4. Comparative temporal expression pattern of homoeologs and singletons. Embryos were collected at different developmental stages from blastula to mid-neurula. The temporal expression pattern of each gene was determined by qPCR. (A) Expression of the $r d h 10 . \mathrm{L}, r d h 10 . S$, and sdr16c5.L genes (Producers 1). (B) Temporal expression pattern of dhrs3.L, dhrs3.S and rdh14.L (Suppressors). (C) Expression pattern of aldh1a2.L, aldh1a2.S, aldh1a3.L and aldh1a3.S (Producers 2).

Figure 5 Responsiveness of homoeologs and singletons to RA manipulations. Embryos were treated from late blastula with $10 \mathrm{nM}$ or $25 \mathrm{nM}$ RA. Samples were collected at early gastrula (st. 10.25) and analyzed by qPCR for the RA responsiveness of individual homoeologs and singletons using the primers listed in Table.1. Expression changes were normalized to transcript levels in control embryos.

\section{Figure 6. Recovery of RA metabolic gene expression following transient RA}

manipulation. (A) Embryos were subjected to a two-hour (T-2 - T0) RA treatment (10 $\mathrm{nM}$ or $25 \mathrm{nM}$ ) from late blastula (st. 9) to early gastrula (st. 10.25). At T0 the treatment was terminated (washed) and the embryos were further incubated. Samples were collected at different times (red and black arrowheads) for expression analysis. (B,C) Kinetic analysis of $r d h 10 . L, r d h 10 . S$, and $s d r 16 c 5$ expression changes. (D,E) qPCR analysis of the expression of dhrs3.L, dhrs3.S, and rdh14. (F,G) Analysis of the aldh1a2.L, aldh1a2.S, aldh1a3.L, and aldh1a3.S expression.

Figure 7. Gene expression changes in RA responsive genes as a result of homoeolog knockdown. RA network component gene specific knockdowns were induced by targeting genes with CRISPR/Cas9. The rdh10.L, rdh10.S, and sdr16c5 (A,C,E,G,I), and 
dhrs3.L and dhrs3.S (B,D,F,H,J) genes were targeted with specific sgRNAs. CRISPant embryos were treated with RA (10 nM) and sibling embryos were treated with RA only as controls. (A,B) Gene expression change analysis at T0 normalized to control expression. (C-J) Kinetic analysis of gene expression changes in CRISPant embryos compared to RA-induced changes at each time point. Genes analyzed: (C,D) cyp26a1.L, (E,F) hoxd1.L/S, (G,H) hoxa1.L, (I,J) hoxa2.L/S.

\section{Figure 8. Regulation tightness score of the RA-responsive genes in CRISPant}

embryos. To calculate the regulation tightness score $(\bullet \bullet)$, the sum of the expression fold change was calculated for the RA-responsive genes: cyp26a1.L, hoxd1.L/S, hoxa1.L, hoxa1.S, hoxa2.L/S, hoxb4.S, hoxb1.L, and hoxb1.S. (A) Analysis in rdh10.L, rdh10.S, and sdr16c5 RA-treated CRISPants. (B)Analysis in dhrs3.L and dhrs3.S RA-treated CRISPants. 


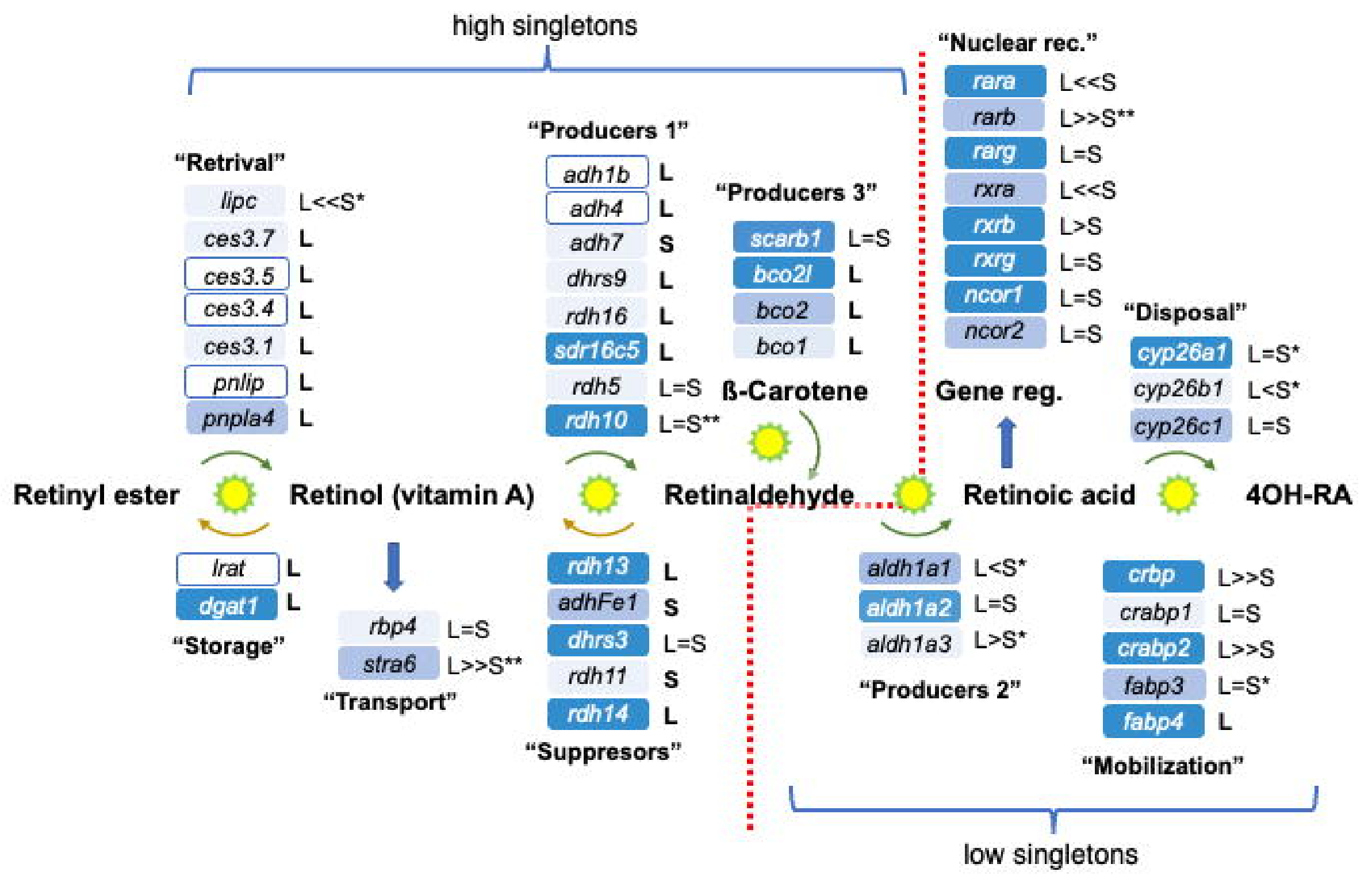




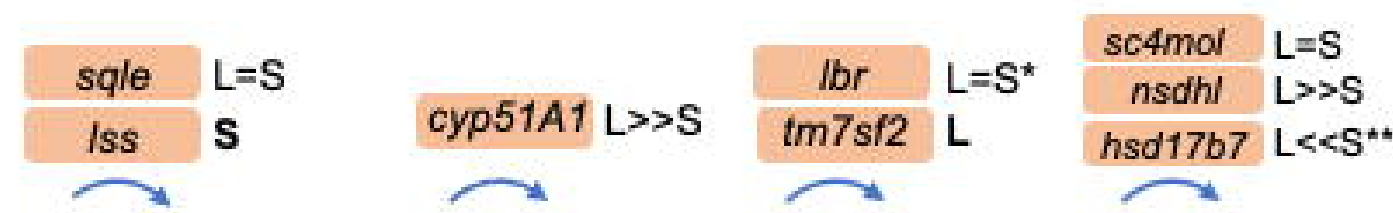

ebp $\mathrm{L}=\mathrm{S} \quad s c 5 d l$ dhar $\mathrm{L}$ L $>\mathrm{S}$

squalene

$\mathrm{L}>\mathrm{S}$ dhcr24

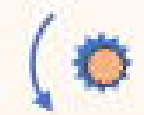

Dihydrolanosterol

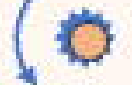

Dihydrolanosterol

$$
\begin{aligned}
& \text { Dihydro- } \\
& \text { ff-MAS }
\end{aligned}
$$

t-MAS

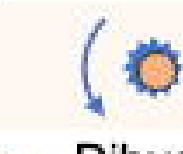

Dihydrot-MAS zymosterol

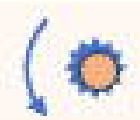

zymostenol

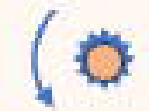

O. lathosterol

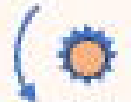

7-dehydrocholesterol

cyp51A1

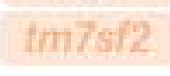

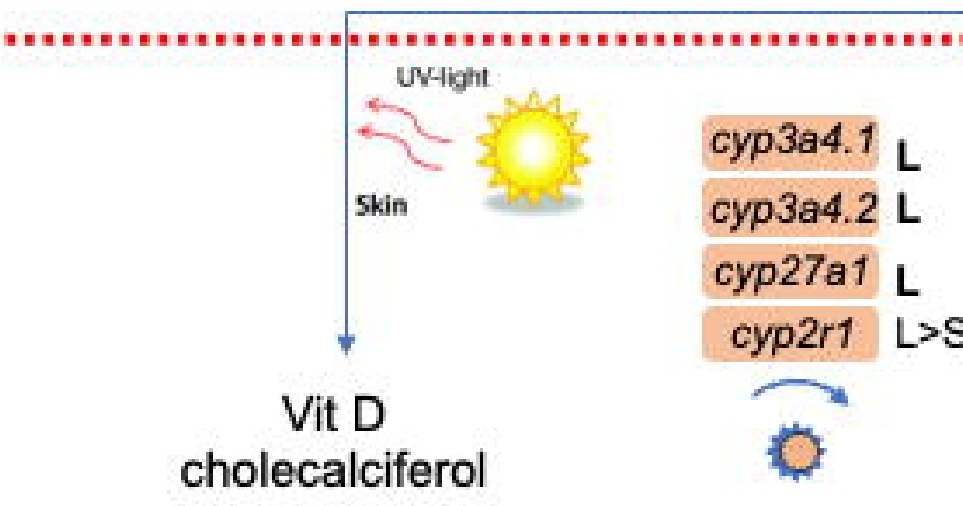

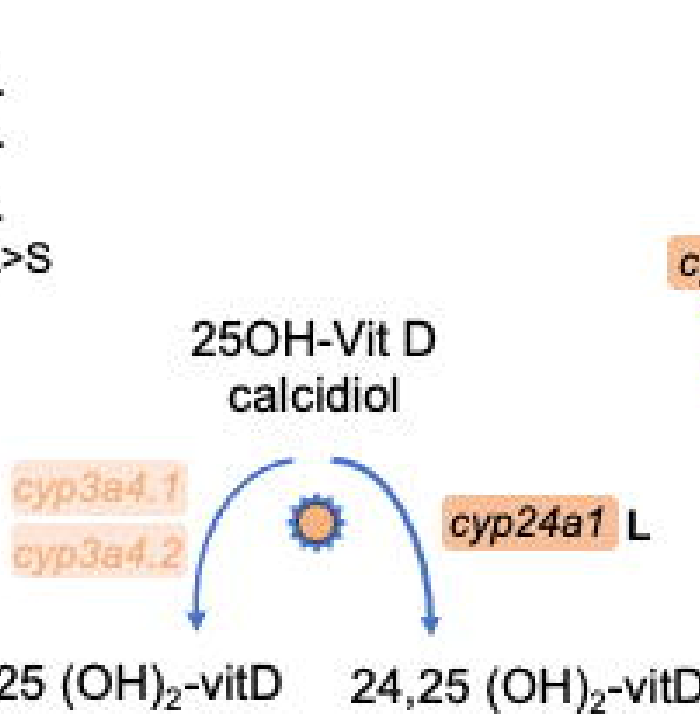

4B,25 $(\mathrm{OH})_{2}$-vitD

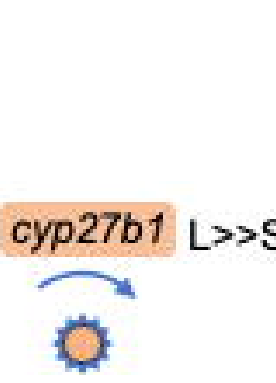

Q

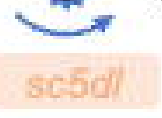

cholesterol

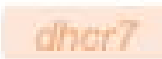

\section{mosterol}

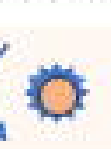

cholesterol 
A Small and simple deletion

chr6S

B Large deletion

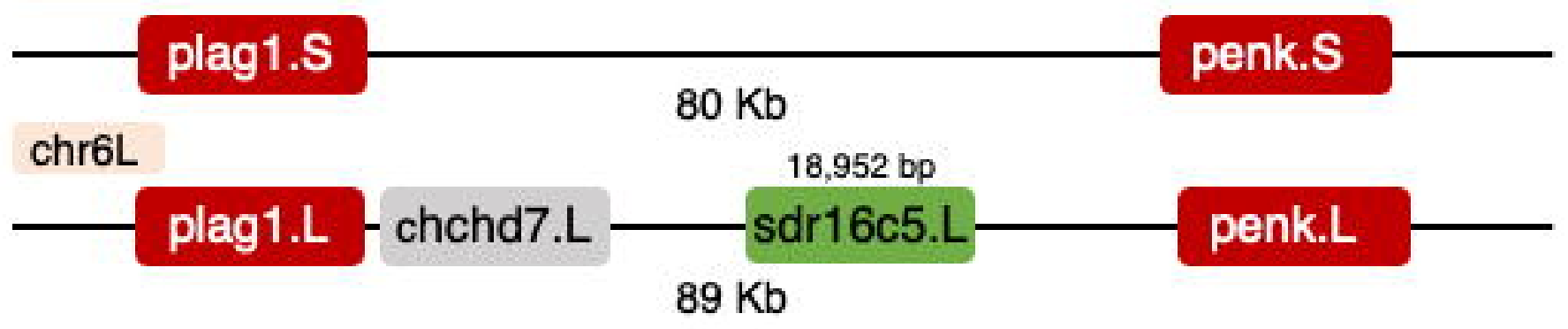

chr2S

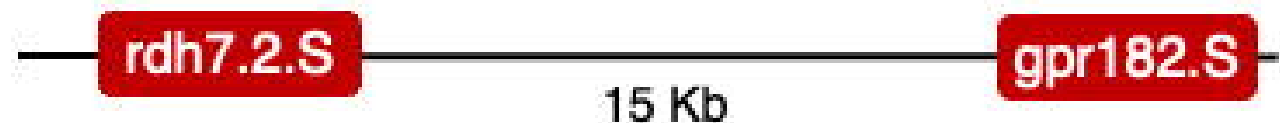

chr2L

$11,580 \mathrm{bp}$

rdh7.2.L XB5807236 rdh16.L rdh7.L LOC108708580- rdh9.L - hsd17b6.L -LOC108708581-gpr182.L $117 \mathrm{~Kb}$

C Complex reorganization and deletion

chr1s

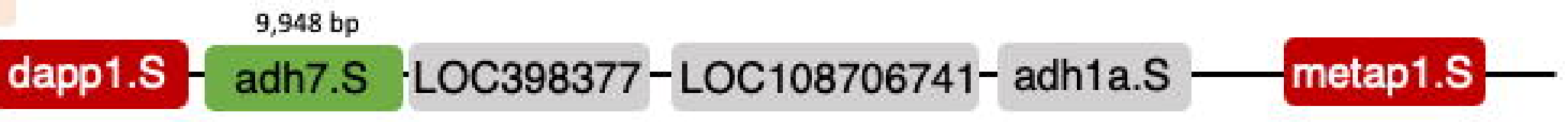

$197 \mathrm{~Kb}$

chr1L

$18,159 \mathrm{bp}$

$13,797 \mathrm{bp}$

$18,689 \mathrm{bp}$

dapp1.L $\cdot$ LOC108710849· MGC83376

adh1b.L

adh4.L - adh1-a -LOC108719623-LOC121403107- adh5.L $278 \mathrm{~Kb}$ 
bioRxiv preprint doi: https://doi.org/10.1101/2022.01.04.474867; this version posted January 4, 2022. The copyright holder for this preprint (which was not certified by peer review) is the author/funder, who has granted bioRxiv a license to display the preprint in perpetuity. It is made available under aCC-BY-NC-ND 4.0 International license.
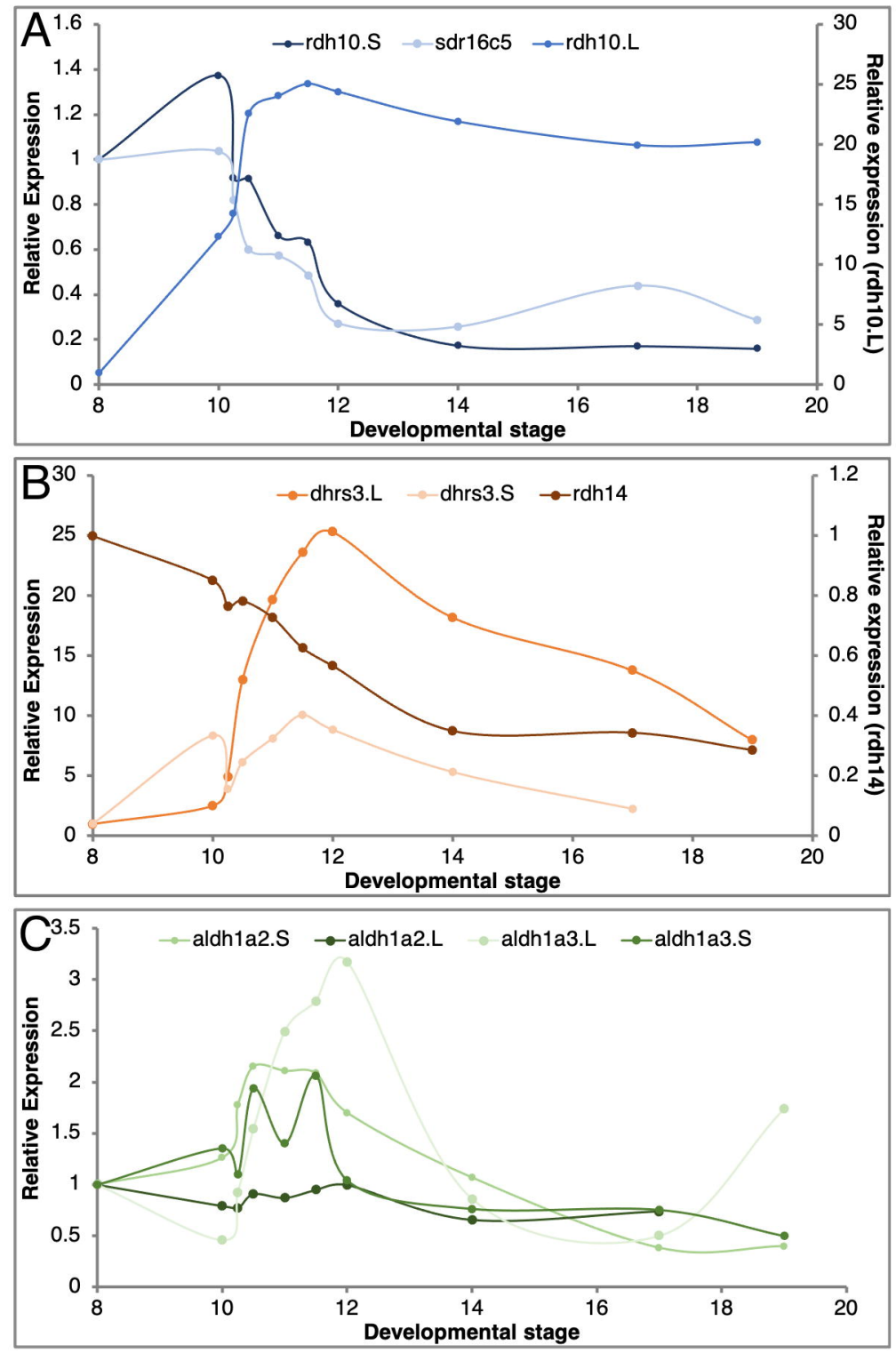


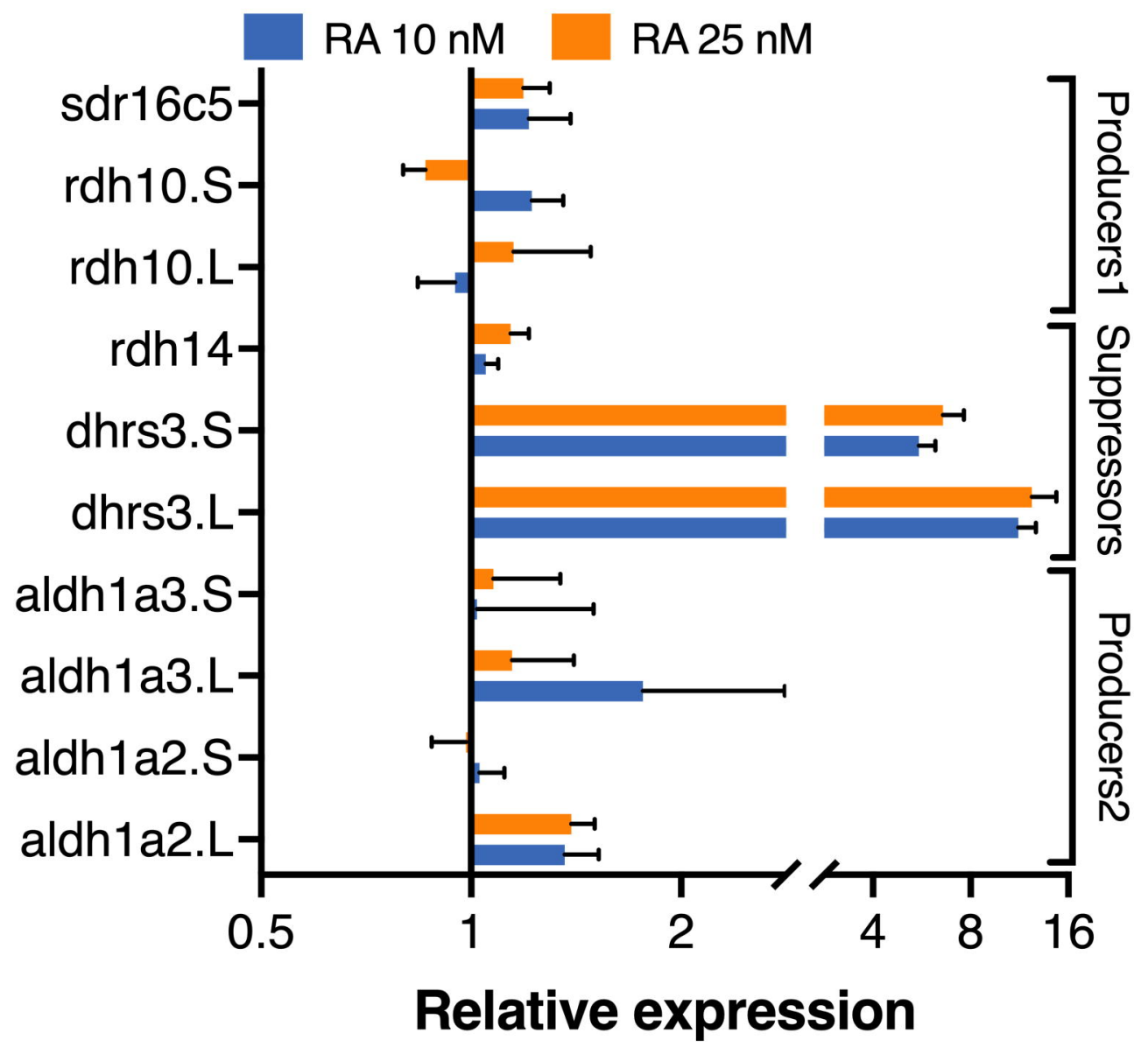


bioRxiv preprint doi: https://doi.org/10.1101/2022.01.04.474867; this version posted January 4, 2022. The copyright holder for this preprint (which was not certified by peer review) is the author/funder, who has granted bioRxiv a license to display the preprint in perpetuity. It is made available under aCC-BY-NC-ND 4.0 International license.
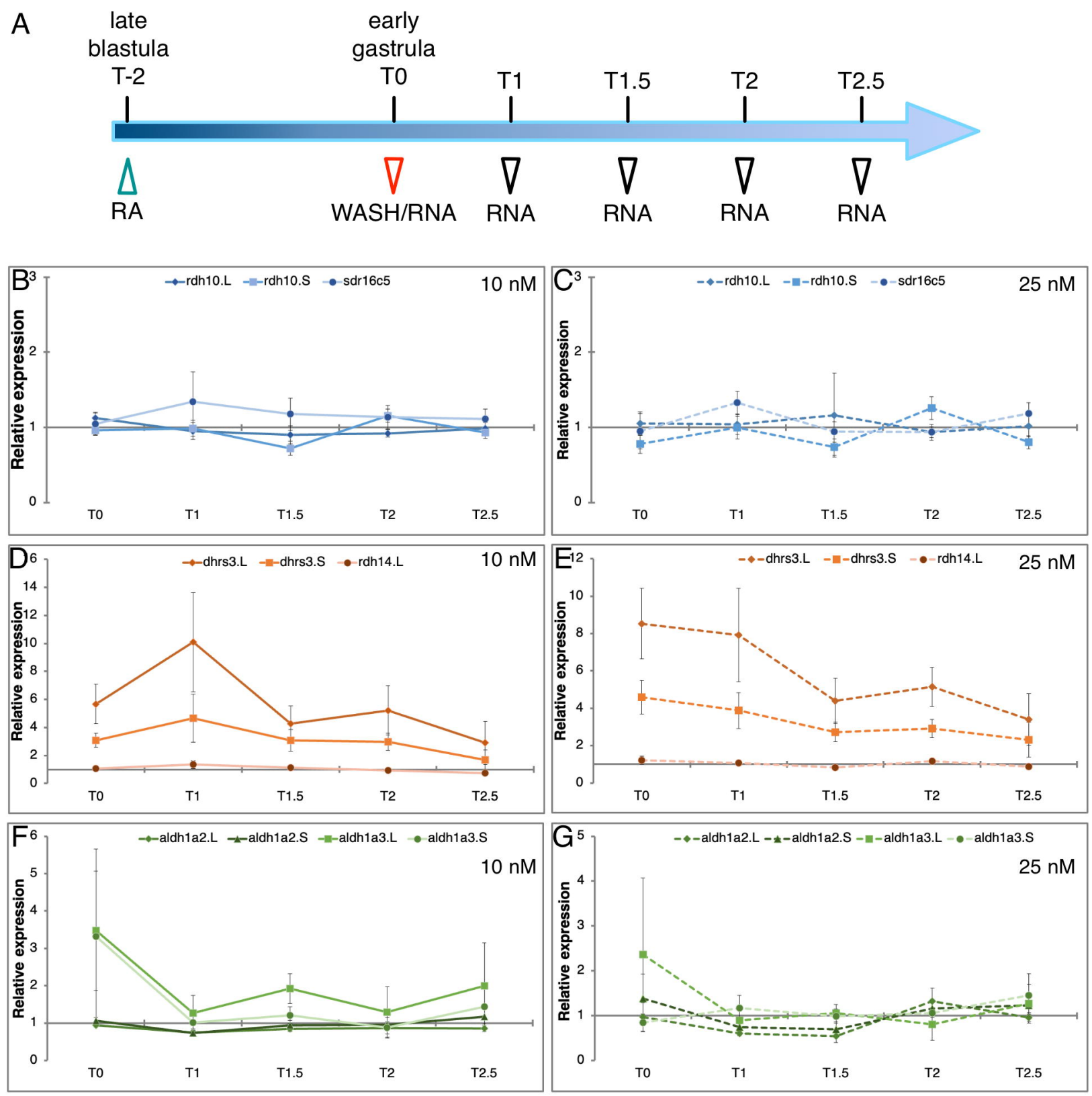


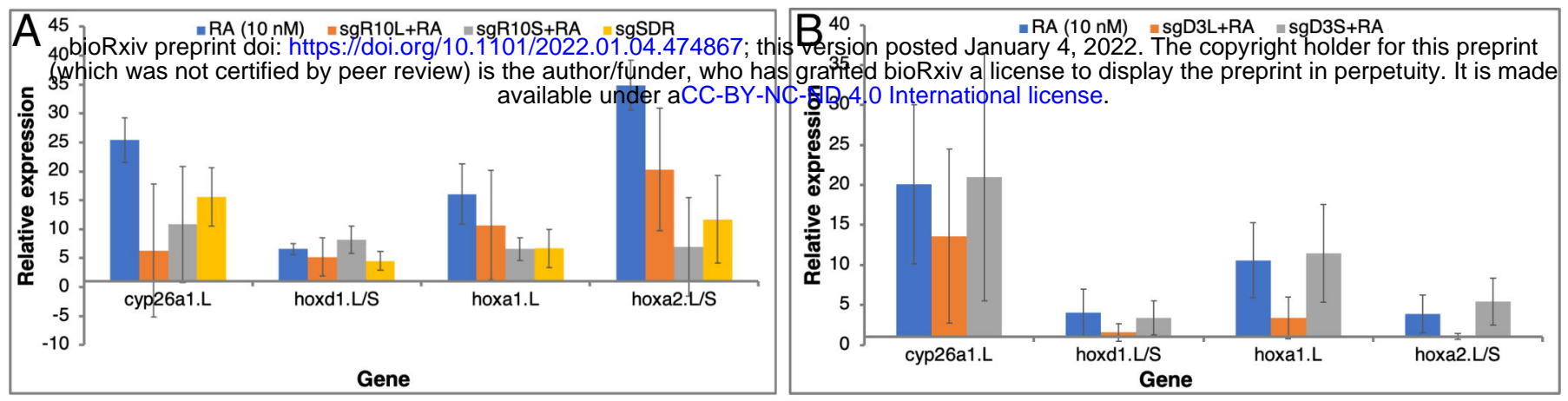

Bersion posted January 4,2022 . The ${ }^{40}$ (10 nM)
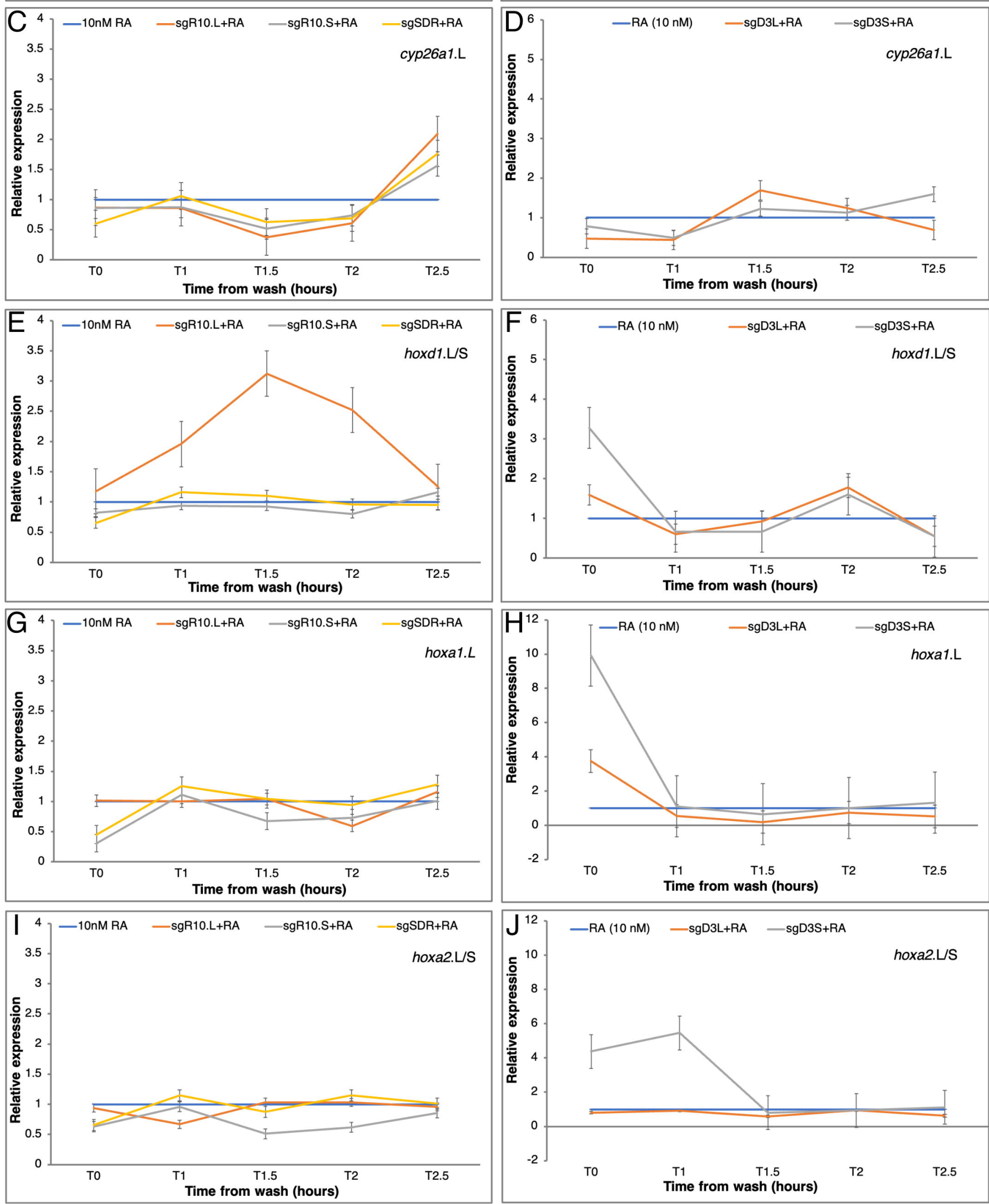
bioRxiv preprint doi: https://doi.org/10.1101/2022.01.04.474867; this version posted January 4, 2022. The copyright holder for this preprint (which was not certified by peer review) is the author/funder, who has granted bioRxiv a license to display the preprint in perpetuity. It is made available under aCC-BY-NC-ND 4.0 International license.
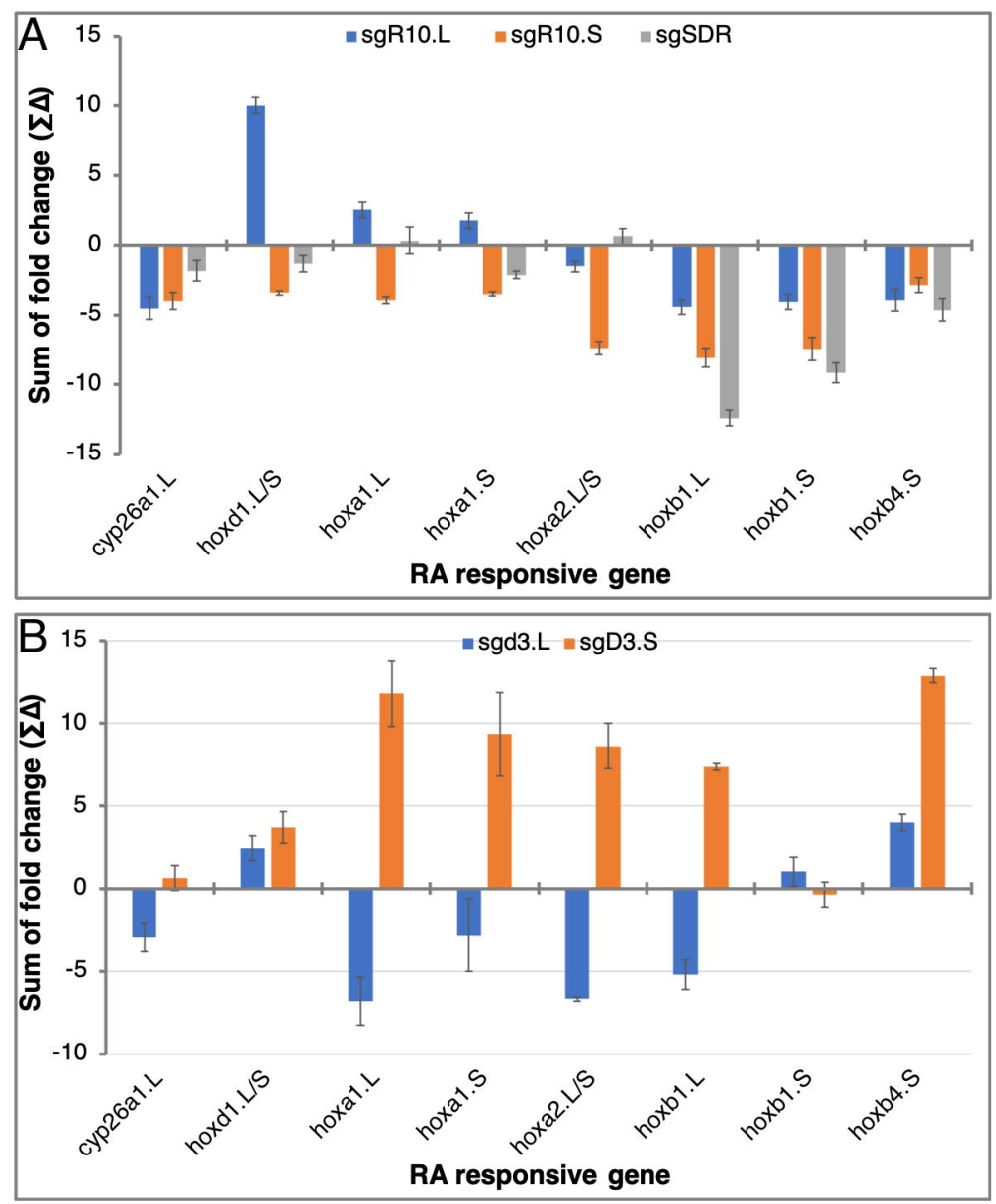